\title{
Modelling carbon overconsumption and the formation of extracellular particulate organic carbon
}

\author{
M. Schartau ${ }^{1}$, A. Engel ${ }^{2}$, J. Schröter ${ }^{2}$, S. Thoms ${ }^{2}$, C. Völker ${ }^{2}$, and D. Wolf-Gladrow ${ }^{2}$ \\ ${ }^{1}$ GKSS-Research Centre, Institute for Coastal Research, Geesthacht, Germany \\ ${ }^{2}$ Alfred Wegener Institute for Polar and Marine Research, Bremerhaven, Germany \\ Received: 30 November 2006 - Published in Biogeosciences Discuss.: 24 January 2007 \\ Revised: 21 May 2007 - Accepted: 1 June 2007 - Published: 2 July 2007
}

\begin{abstract}
During phytoplankton growth a fraction of dissolved inorganic carbon (DIC) assimilated by phytoplankton is exuded in the form of dissolved organic carbon (DOC), which can be transformed into extracellular particulate organic carbon (POC). A major fraction of extracellular POC is associated with carbon of transparent exopolymer particles $($ TEP; carbon content $=$ TEPC) that form from dissolved polysaccharides (PCHO). The exudation of $\mathrm{PCHO}$ is linked to an excessive uptake of DIC that is not directly quantifiable from utilisation of dissolved inorganic nitrogen (DIN), called carbon overconsumption. Given these conditions, the concept of assuming a constant stoichiometric carbon-tonitrogen $(\mathrm{C}: \mathrm{N})$ ratio for estimating new production of POC from DIN uptake becomes inappropriate. Here, a model of carbon overconsumption is analysed, combining phytoplankton growth with TEPC formation. The model describes two modes of carbon overconsumption. The first mode is associated with DOC exudation during phytoplankton biomass accumulation. The second mode is decoupled from algal growth, but leads to a continuous rise in POC while particulate organic nitrogen (PON) remains constant. While including PCHO coagulation, the model goes beyond a purely physiological explanation of building up carbon rich particulate organic matter (POM). The model is validated against observations from a mesocosm study. Maximum likelihood estimates of model parameters, such as nitrogen- and carbon loss rates of phytoplankton, are determined. The optimisation yields results with higher rates for carbon exudation than for the loss of organic nitrogen. It also suggests that the PCHO fraction of exuded DOC was $63 \pm 20 \%$ during the mesocosm experiment. Optimal estimates are obtained for coagulation kernels for $\mathrm{PCHO}$ transformation into TEPC. Model state estimates are consistent with observations, where $30 \%$ of the POC increase was attributed to
\end{abstract}

Correspondence to: M. Schartau

(markus.schartau@gkss.de)
TEPC formation. The proposed model is of low complexity and is applicable for large-scale biogeochemical simulations.

\section{Introduction}

Marine biogeochemical modelling predominantly aims at quantifying carbon, nitrogen, and phosphorus fluxes within the ocean. For that, understanding the biological transformation of dissolved nutrients into particulate organic matter $(\mathrm{POM})$ is critical to devising biogeochemical- or ecosystem models. Yet, typical nitrogen or phosphorus based ecosystem models have difficulties in matching equally well in-situ primary production rates and standing stock observations, such as chlorophyll $a(\mathrm{Chl} a)$ concentrations, (Fasham et al., 1993; Fasham and Evans, 1995; Schartau and Oschlies, 2003b). This becomes evident shortly after phytoplankton growth has run into nutrient depletion. To some extent these model deficiencies are seen when simulating the magnitude and timedepth distribution of particulate organic carbon (POC) formation. The formation of POC is often modelled proportional to the build-up of phytoplankton nitrogen or phosphorus biomass; fixed stoichiometric carbon-to-nitrogen $(\mathrm{C}: \mathrm{N})$ or carbon-to-phosphorus (C:P) ratios (Redfield et al., 1963; Takahashi et al., 1985) are prescribed as a proportionality factor. As a consequence, the modelled transformation of dissolved inorganic carbon (DIC) into biomass remains highly correlated with the utilisation of dissolved inorganic nitrogen (DIN) and phosphate by phytoplankton.

Today, marine biologists question a strict, linear correlation between nitrogen utilisation and carbon uptake (e.g. Falkowski, 2000; Sorensen and Siegel, 2001; Geider and LaRoche, 2002), and biogeochemical models with constant $\mathrm{C}: \mathrm{N}$ and $\mathrm{C}: \mathrm{P}$ stoichiometric ratios are therefore expected to have significant limitations. When a constant molar $\mathrm{C}: \mathrm{N}$ ratio of 106:16 is applied to derive the uptake of DIC from the utilisation of DIN by phytoplankton, differences between

Published by Copernicus Publications on behalf of the European Geosciences Union. 
derived and observed uptake rates can be obtained that cannot be explained by physical or chemical dynamics alone (Sambrotto et al., 1993; Broström, 1998; Körtzinger et al., 2001).

The uptake of more DIC than expected from nitrate or phosphate removal was termed carbon overconsumption by Toggweiler (1993). For example, when either nitrate or phosphate becomes depleted, photosynthesis can still proceed and carbon uptake need not automatically cease (e.g. Banse, 1994). In general, an excess DIC uptake by phytoplankton is understood as being exclusively channelled through the pool of labile dissolved organic carbon (DOC) (e.g. Anderson and Williams, 1999; Kaehler and Koeve, 2001) that is eventually turned over by heterotrophic bacteria. Such a labile fraction of DOC is unlikely to be significant for long-term carbon removal from the upper ocean (Carlson et al., 1998). This would entail a negligible impact of carbon overconsumption on the biological carbon pump. An alternative pathway is the release of dissolved organic matter (DOM) by phytoplankton followed by the formation of particulate organic matter (POM) and, at best, the export of carbon to the deeper ocean. Such a linkage between DOM and POM (linking the release of polysaccharides to the formation of larger colloidal particles, which are measured as transparent exopolymer particles, TEP) has been shown by Mopper et al. (1995), Zhou et al. (1998), and Engel and Passow (2001). Since TEP is relevant for the dynamics of phytoplankton aggregation, it was presumed to be involved in the removal of DOM and the export of POM. In the studies of Mopper et al. (1995) and Zhou et al. (1998) a transformation of DOM precursors to TEP was investigated qualitatively. Hereupon, different underlying mechanisms have been discussed for this transformation (Passow, 2002).

Two mechanisms have been proposed for TEP formation, spontaneous assembly (Chin et al., 1998) and particle coagulation (e.g. Logan et al., 1995) respectively. A TEP size spectrum analysis eventually provided evidence that TEP formation from DOM can be well described with coagulation dynamics (Mari and Burd, 1998). Subsequent studies have picked up these preceding ideas but focused on the actual carbon content of TEP (TEPC) and its biogeochemical conjunction with DIC uptake, gross primary production and DOC exudation (Mari et al., 2001; Engel et al., 2002). In a recent study, the cascade from the exudation of acidic polysaccharides (PCHO) to TEPC formation has been quantitatively assessed and the TEPC increase was successfully described with a simple parameterisation of the PCHO-TEP dynamics (Engel et al., 2004). Engel et al. (2004) parameterised the complex process of polysaccharide aggregation in terms of a two size-class model, which describes the interaction between PCHO and TEPC. This simplified approach was derived from a full size-class resolved model (Smoluchowski equations) by assuming that the coagulation dynamics, under typical PCHO background concentrations, is close to steady state. Our understanding of the non-linear cou- pling between PON and POC formation has improved during the last decade: We learned that the decoupling does not solely result from stoichiometric variations within phytoplankton cells or from differential remineralisation, but can also result from extracellular PCHO coagulation. We believe that it is deemed necessary to account for such a process in biogeochemical- and ecosystem models used for carbon flux studies, in particular since it indirectly affects the aggregation and sinking of phytoplankton (Jackson, 2001), and thus mediates organic carbon export in the oceans.

With this study we propose a model that resolves the cascade from decoupled carbon and nitrogen assimilation by phytoplankton to the formation of extracellular POC. We provide maximum likelihood based estimates of uncertain and unknown model parameter values. The overall model is kept simple enough to become potentially suited for largescale biogeochemical simulations. Here, we validate the model's ability to combine processes that are often regarded separately: 1) phytoplankton acclimation to nitrogen stress, 2) carbon overconsumption, and 3) exudation and coagulation of DOC. The model is calibrated with data from a mesocosm experiment, as presented in Engel et al. (2002). A bootstrapping approach is applied for parameter optimisation, in order to approximate errors for optimal parameter estimates. Special focus of our modelling approach is on simulating the increase of TEPC, and their formation from the precursors PCHO. With our analysis we approximate the PCHO fraction of total DOC exudates and obtain maximum likelihood estimates of carbon specific coagulation kernels relevant for TEPC formation.

\section{Method}

\subsection{Model description}

The model setup was chosen to reproduce conditions of a mesocosm experiment, as described in Engel et al. (2002). The mesocosm experiment was performed in a tank of $0.9 \mathrm{~m}$ height that was continuously stirred over a period of 20 days. The mean temperature was $12.5^{\circ} \mathrm{C}$. A halogen light source provided a surface irradiance of $26 \mathrm{~W} \mathrm{~m}^{-2}$ (approx. $115 \mu$ mol photons $\mathrm{m}^{-2} \mathrm{~s}^{-1}$ ) with a light:dark cycle of 14:10 h. 1226 liters of water were collected in the Santa Barbara channel at $6 \mathrm{~m}$ depth, and sand filtered before being filled into the tank. The initial concentration of DIN was $35.5 \mathrm{mmol} \mathrm{N} \mathrm{m}^{-3}$. Observations are available at 17 sampling dates, covering a period of 20 days.

\subsubsection{Phytoplankton growth}

For this study we chose to adopt the growth parameterisations of Geider et al. (1998), which is often used as a basis for marine ecosystem models (e.g. Moore et al., 2001; Lima and Doney, 2004). We only changed the step function for the maximum nitrate uptake rate (Eq. B7 in the 
Appendix). The function suggested by Geider et al. (1998) is non-mechanistic and was formulated solely to simulate a rapid decline in nitrate uptake when a maximum cellular nitrogen-to-carbon $\left(q_{\max }\right)$ ratio is reached. Our formulation is also non-mechanistic, but avoids the strongly non-linear discontinuity in the vicinity of $q_{\max }$, yet showing the same step characteristics. All other equations for phytoplankton growth remain identical to those proposed in Geider et al. (1998). Primary production is regulated by light availability $(I)$, temperature $(T)$, dissolved nutrient concentrations, and a variable cellular nitrogen-to-carbon ratio $(q)$. The exact initial phytoplankton biomass was unknown (below detection limit; $\left.<0.1(\mathrm{mmol} \mathrm{N}) \mathrm{m}^{-3}\right)$ but variations of small initial phytoplankton concentrations may result in biased parameter estimates. Therefore, the initial nitrogen biomass of the phytoplankton was optimised in conjunction with the other model parameters. The estimated initial nitrogen biomass is converted to carbon units assuming a molar Redfield ratio of $\mathrm{C}: \mathrm{N}=106: 16$. Accordingly, the chlorophyll $a$ concentration $(\mathrm{Chl} a)$ is derived by applying a factor of $1.56 \mathrm{mg}$ $\mathrm{Chl} a(\mathrm{mmol} \mathrm{N})^{-1}$. We extended the phytoplankton growth model to a small ecosystem model that resolves nutrients, heterotrophic activity, the formation of detritus, leakage and exudation of DOM.

\subsubsection{DOM and TEPC}

In this study we focus on DOM exudation and extracellular POC formation. Apart from the variable $\mathrm{C}: \mathrm{N}$ stoichiometry during phytoplankton growth, we also account for carbon and nitrogen decoupling as a result of TEPC formation. To accomplish this, the DOM pool represented in the model only consists of freshly exuded, labile compounds. Refractory DOM remains unresolved. The labile DOM pool is split up into PCHO, residual dissolved carbon (resDOC), and organic nitrogen compounds (DON). TEPC is regarded as a separate state variable. Residual DOC and DON are unspecified fractions of DOM. Carbon overconsumption by phytoplankton is not only expressed by changes in cell quota but also in the nitrogen-to-carbon $(\mathrm{N}: \mathrm{C})$ ratio of DOM. The complex process of polysaccharide aggregation is parameterised in terms of a two size-class model, which describes the interaction between PCHO and TEPC (Engel et al., 2004). This two-size class model relates the exudation of PCHO to the formation of TEPC and hence provides the key to understanding the decoupling of PON and POC formation, in particular if it is assumed that TEPC becomes largely detected as POC (Engel et al., 2002). In practice, cell lysis, exudation, and leakage of organic matter cannot be constrained separately. For this reason we solely distinguish between a carbon and a nitrogen loss rate. This separation becomes relevant because active exudation of cellular carbon happens at times when organic nitrogen is only passively lost by phytoplankton in smaller quantities.
2.1.3 Dissolved inorganic carbon (DIC), DIN, and total alkalinity (TA)

Assuming thermodynamical equilibrium, the carbonate chemistry is constrained by two state variables, namely TA and DIC. TA in the model varies with the DIN and phosphorus acquisition by phytoplankton and with remineralisation. In the model the unresolved phosphorus contribution to TA is assumed to be linearly linked to the nitrogen fluxes through the application of a constant nitrogen-to-phosphorus $(\mathrm{N}: \mathrm{P})$ ratio of 16 . The flux of carbon dioxide $\left(\mathrm{CO}_{2}\right)$ between the mesocosm and the air is calculated from temperature, DIC, and TA with a routine from the Ocean Carbon-Cycle Model Intercomparision Project (OCMIP; Orr, 1999), using a parameterisation for gas transfer velocity (Wanninkhof and Knox, 1996) that takes into account the enhancement of gas exchange by hydration reactions of $\mathrm{CO}_{2}$ under very low wind conditions. A constant atmospheric $\mathrm{pCO}_{2}$ of $370 \mu \mathrm{atm}$ is prescribed for the entire period of model integration. Measured values of DIN, TA, and DIC at the beginning of the experiment were taken as initial conditions.

\subsubsection{Detritus}

Apart from leakage and exudation, additional phytoplankton nitrogen and carbon losses are associated with cell lysis due to bacterial and viral activity, and grazing by zooplankton. Fragments of cellular material, as a result of cell death, are described as a detrital compartment in the model. Also, the biomass of phytoplankton aggregates enters the detrital pool, assuming that no significant primary production occurs within particle aggregates. This assumption has limitations but a detailed description of active cells among dead cellular material in particle aggregates is beyond the scope of this study. Similar to the aggregation parameterisation of PCHO and TEPC, we used an approach for phytoplankton aggregation that has been tested by Ruiz et al. (2002) against a multi-size-class model, which in turn was calibrated with coulter counter observations. In Ruiz et al. (2002) it was shown that a zero order model, with two size class formulation, already captures the predominant particle dynamics, when compared with observations. We will use their parameterisation together with their parameter values. In the model, particulate matter of detritus is linearly degraded until it becomes dissolved, turning into resDOC. The pools of resDOC and DON are mineralised to DIC and DIN respectively.

\subsubsection{Heterotrophs}

In the mesocosm experiment, the heterotrophic activity remained small. This was inferred from oxygen measurements that were used to determine gross- and net community production. A heterotrophic compartment is included as a closure for modelling the nitrogen and carbon fluxes of the mesocosm experiment. The degree of freedom that is added 


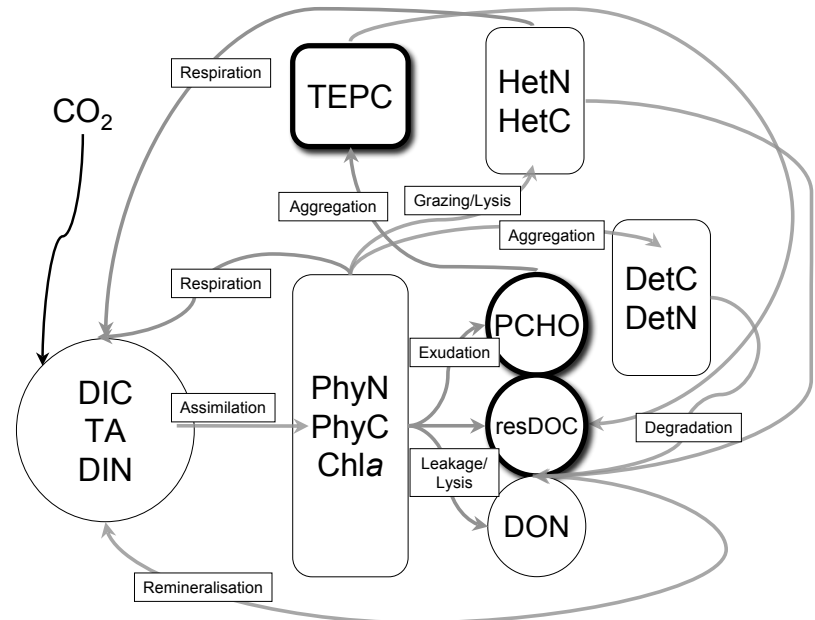

Fig. 1. Structure of the model for simulations of nitrogen- and carbon fluxes, as observed during a mesocosm experiment. The model splits dissolved organic carbon (DOC) into two fractions, polysaccharides (PCHO) and the residual dissolved organic carbon (resDOC). From dissolved inorganic carbon (DIC) and total alkalinity (TA) the actual partial pressure of carbon dioxide $\left(\mathrm{pCO}_{2}\right)$ is determined, which provides gradient information for the air-water gas exchange. Phytoplankton carbon (PhyC) is distinguished from the nitrogen biomass (PhyN) and chlorophyll a (Chl $a)$. Phytoplankton leaks dissolved organic nitrogen (DON), which is mineralised. Transparent exopolymeric particles (TEP) are formed by coagulation of PCHO. All TEP is modelled in carbon units (TEPC). Phytoplankton cells can aggregate, forming detrital nitrogen (DetN) and carbon (DetC).

to the model, by implementing the heterotrophic compartment, is not critical since it can be constrained by the measured net- and gross community production rates. An explicit representation of bacteria, protists, and meso-zooplankton for this modelling study, however, is considered as redundant unless their respective impact on PCHO exudation and TEPC formation can be well characterised.

The model is run for 22 days. Overall, fourteen state variables simulate the dominant nitrogen and carbon fluxes within the mesocosm, Fig. 1. An Euler forward scheme was chosen for numerical integration. A timestep of 5 min turned out to be appropriate. Any further decrease in timestep did not yield different model results. A stochastic parameter optimisation then becomes applicable within reasonable computational time. The full model equations are listed in the Appendix.

2.2 Data assimilation and maximum likelihood estimation of parameter values

\subsubsection{Definition of cost function}

The form of our cost function used for optimisation can be derived from a Bayesian approach to data analysis. In the context of parameter estimation Bayes theorem reads $\operatorname{prob}(\mathbf{p} \mid \mathbf{d}, \mathbf{H}, I)=\operatorname{prob}(\mathbf{d} \mid \mathbf{p}, \mathbf{H}, I) \cdot \frac{\operatorname{prob}(\mathbf{p} \mid \mathbf{H}, I)}{\operatorname{prob}(\mathbf{d} \mid \mathbf{H}, I)}$

where $\mathbf{p}$ is the array of unknown model parameters to be estimated from data, $\mathbf{d}$, under the hypothesis $\mathbf{H}$ (= model equations) and background information $I$.

We apply a uniform prior, i.e. $\operatorname{prob}(\mathbf{p} \mid \mathbf{H}, I)$ is is a constant within prescribed upper and lower limits of plausible parameter values. Beyond these limits, the prior probability becomes zero. In our case, the possibility for parameter estimates is specified by the inverse of the number of increments within the upper and lower limits. In the context of parameter estimation the denominator $\operatorname{prob}(\mathbf{d} \mid \mathbf{H}, I)$ is used as a normalisation factor, i.e. it is also a constant. Thus the probability distribution for the parameters, $\operatorname{prob}(\mathbf{p} \mid \mathbf{d}, \mathbf{H}, I)$, is proportional to the so-called likelihood

$L(\mathbf{d} \mid \mathbf{p}, \mathbf{H}, I) \propto \operatorname{prob}(\mathbf{d} \mid \mathbf{p}, \mathbf{H}, I)$.

Because of this proportionality, an increase of the probability $\operatorname{prob}(\mathbf{p} \mid \mathbf{d}, \mathbf{H}, I)$ becomes tantamount to maximising the likelihood $L(\mathbf{d} \mid \mathbf{p}, \mathbf{H}, I)$.

All data are assumed to be independent, therefore the likelihood function is given by the product of $M \cdot N$ ( $M$ types of observations, $N$ sampling dates) probabilities:

$L(\mathbf{d} \mid \mathbf{p}, H, I)=\prod_{i=1}^{M} \prod_{j=1}^{N} \frac{1}{\epsilon_{i} \sqrt{2 \pi}} \exp \left[-\frac{\left(m_{i j}-d_{i j}\right)^{2}}{2 \epsilon_{i}^{2}}\right]$

A Gaussian distribution is assumed for model variables $\left(m_{i j}\right)$ being able to match observations $\left(d_{i j}\right)$ with variance $\epsilon_{i}^{2}$. Maximising the likelihood is equivalent to minimising the negative logarithm of the likelihood

$$
\begin{aligned}
-\ln (L) & =\sum_{i=1}^{M}\left(-N \cdot \ln \left(\frac{1}{\epsilon_{i} \sqrt{2 \pi}}\right)+\sum_{j=1}^{N} \frac{1}{2 \epsilon_{i}^{2}}\left(m_{i j}-d_{i j}\right)^{2}\right) \\
& =\text { constant }+\underbrace{\sum_{i=1}^{M} \sum_{j=1}^{N} \frac{1}{2 \epsilon_{i}^{2}}\left(m_{i j}-d_{i j}\right)^{2}}_{=J \text { (cost function) }}
\end{aligned}
$$

or minimising the cost function $J$ which simply consists of the sum over the weighted least square data-model deviations.

There are $M=8$ different types of observations available: 1. dissolved inorganic nitrogen (DIN), 2. dissolved inorganic carbon (DIC), 3. chlorophyll $a$ (Chla), 4. particulate organic nitrogen (PON), 5. particulate organic carbon (POC), 6. carbon content of transparent exopolymer particles (TEPC), 7. gross primary production (GPP), 8. net community production (NCP). The duration of the experiment was $T=20$ days and samples were taken on 17 days $(N=17)$. Finally, we introduce information with respect to the accuracy of sampling times. The misfit between model results and data are 
Table 1. Model parameters, which remain fixed and do not enter the optimisation procedure.

\begin{tabular}{|c|c|c|}
\hline Fixed parameters & Symbol & Value \& Unit \\
\hline Chl $a$-specific photosynthetic efficiency & $\alpha_{\mathrm{Chl}}$ & $0.3 \mathrm{mmol} \mathrm{C}(\mathrm{mg} \mathrm{Chl} a)^{-1} \mathrm{~m}^{2} \mathrm{~W}^{-1} \mathrm{~d}^{-1}$ \\
\hline Half-saturation constant for DIN uptake & $\mathrm{k}_{\mathrm{DIN}}$ & $1.0 \mathrm{mmol} \mathrm{N} \mathrm{m}^{-3}$ \\
\hline Biosynthetic costs & $\zeta$ & $2.3 \mathrm{mmol} \mathrm{C} \mathrm{mmol} \mathrm{N}^{-1}$ \\
\hline Chl $a$ degradation & $\gamma_{\mathrm{chl}}$ & $0.001 \mathrm{~d}^{-1}$ \\
\hline Maintenance respiration rate & $\mathrm{r}_{\mathrm{C}}$ & $0.01 \mathrm{~d}^{-1}$ \\
\hline Phytoplankton quadratic aggregation loss & $\Phi_{P P}$ & $0.02 \mathrm{~m}^{6} \mathrm{mmol} \mathrm{N}^{-2} \mathrm{~d}^{-1}$ \\
\hline Degradation of TEPC & $\rho_{*}^{C}$ & $0.01 \mathrm{~d}^{-1}$ \\
\hline Molar $\mathrm{C}: \mathrm{N}$ ratio & Redfield & 6.625 \\
\hline Minimum molar cellular $\mathrm{N}$ : $\mathrm{C}$ ratio & $q_{\min }$ & 0.043 \\
\hline Maximum molar cellular $\mathrm{N}: \mathrm{C}$ ratio & $q_{\max }$ & 0.171 \\
\hline Maximum cellular Chl $a: \mathrm{N}$ ratio & $\theta_{N}^{\max }$ & $4.2 \mathrm{mg} \mathrm{mmol}^{-1}$ \\
\hline Slope parameter for DIN-uptake regulation & $\sigma_{C}^{N}$ & $1000 \mathrm{mmol} \mathrm{N}^{2}(\mathrm{mmol} \mathrm{C})^{-2}$ \\
\hline Relaxation for heterotrophic respiration & $\tau_{\text {het }}$ & $0.05 \mathrm{~d}^{-1}$ \\
\hline Loss rate for heterotrophs & $\gamma_{\text {het }}$ & $0.001 \mathrm{~d}^{-1}$ \\
\hline Half-saturated phytoplankton loss to herbivory & $\epsilon$ & $1.0 \mathrm{mmol} \mathrm{N}^{2} \mathrm{~m}^{-6}$ \\
\hline Slope of Arrhenius relation & $A_{E}$ & $4500 \mathrm{~K}$ \\
\hline Reference temperature for $A_{E}$ relation & $T_{\text {ref }}$ & $288.15 \mathrm{~K}$ \\
\hline C-specific collision kernel PCHO-PCHO & $\beta_{\mathrm{PCHO}}$ & $0.86 \mathrm{~m}^{3}(\mathrm{mmol} \mathrm{C})^{-1} \mathrm{~d}^{-1}$ \\
\hline C-specific collision kernel PCHO-TEPC & $\beta_{\text {TEPC }}$ & $0.064 \mathrm{~m}^{3}(\mathrm{mmol} \mathrm{C})^{-1} \mathrm{~d}^{-1}$ \\
\hline Particle stickiness PCHO-PCHO & $\alpha_{\mathrm{PCHO}}$ & $0.87 \times 10^{-3}$ \\
\hline Particle stickiness PCHO-TEPC & $\alpha_{\text {TEPC }}$ & 0.4 \\
\hline
\end{tabular}

usually calculated at discrete points in time. In cases where time lags are present in sampling, the parameter optimisation is then affected, and additional bias is introduced to the parameter estimates. In order to take into account uncertainties in sampling time, we bring in time dependent variance information. The error variance is assumed to be infinite at times far away from sampling, which means that the data information remains infinitely small. But, as time approaches the specified moment of sampling, the data information of the measurement becomes significant. A Gaussian error distribution is assumed around the prescribed point in time of the $j$ 'th measurement on date $\left(\tau_{j}\right)$. A sampling uncertainty of one hour is defined as variance $\left(\sigma_{t}=1 \mathrm{~h}\right)$. The time dependency of the observational error can be described as:

$\epsilon_{i j}(t)^{2}=\frac{\sigma_{i}^{2}}{E\left(t, \tau_{j}\right)}$

with

$E\left(t, \tau_{j}\right)=\frac{1}{\sqrt{2 \pi \sigma_{t}^{2}}} \exp \left[-\frac{\left(t-\tau_{j}\right)^{2}}{2 \sigma_{t}^{2}}\right]$
The final cost function, which becomes subject to minimisation, is:

$J=\sum_{i=1}^{M} \sum_{j=1}^{N} \int_{t=0}^{T} \frac{E\left(t, \tau_{j}\right)}{2 \sigma_{i}^{2}}\left(m_{i}(t)-o_{i j}\right)^{2} d t$

In the limit $\sigma_{t} \rightarrow 0$ the Gaussian Eq. (6) becomes the $\delta$ distribution $\delta_{j}\left(t-\tau_{j}\right)$. Inserting the $\delta$ distribution into Eq. (7) and integration over $t$ leads us back to Eq. (4), with $\epsilon_{i}^{2}=\sigma_{i}^{2}$. Table A1 summerizes the assumed error variances $\left(\sigma_{i}^{2}\right)$ that enter our calculations. Under ideal conditions, a perfect model fit to observations would yield a minimum of the cost function close to the value of expectation of $N \cdot M-\operatorname{dim}(\mathbf{p})=122$ (number of independent measurements minus the number of adjustable model parameters). Nevertheless, this value can only be achieved, if the exact moment of sampling was known $\left(\sigma_{t}=0\right)$, if observations were truly independent, if the assumed error variances were true, and if model equations would describe the ecosystem dynamics precisely.

\subsubsection{Estimation of parameter values and errors}

The model includes 31 parameters. We can assign fixed values to 17 parameters that are either well constrained or 
Table 2. Model parameters used for optimisation. Some parameters describe only a multiplicative factor by which an initial value is modified $\left(\Phi_{P D}, \Phi_{\mathrm{PCHO}}, \Phi_{\mathrm{TEPC}}\right)$. The initial values are taken from literature and are described in the Equation section of in the Appendix.

\begin{tabular}{lll}
\hline Parameters for variation & Symbol & Unit \\
\hline 1) Parameter for carbon-specific photosynthesis & $\mu_{C}$ & $d^{-1}$ \\
2) Phytoplankton linear nitrogen loss rate & $\gamma_{N}$ & $d^{-1}$ \\
3) Phytoplankton linear carbon loss rate & $\gamma_{C}$ & $d^{-1}$ \\
4) Remineralisation of DON & $\rho_{N}$ & $d^{-1}$ \\
5) Remineralisation of resDOC & $\rho_{C}$ & $d^{-1}$ \\
6) Deviation from a priori guess on Phy-Det aggregation & $\Phi_{P D}$ & 1 \\
7) Remineralisation of detrital nitrogen & $\omega_{N}$ & $d^{-1}$ \\
8) Remineralisation of detrital carbon & $\omega_{C}$ & $d^{-1}$ \\
9) Nitrogen specific grazing rate & $g_{m}$ & $d^{-1}$ \\
10) Polysaccharide fraction of total DOC exudates & $f_{\mathrm{PCHO}}$ & 1 \\
11) Deviation from a priori guess on PCHO-PCHO coagulation & $\Phi_{\mathrm{PCHO}}$ & 1 \\
12) Deviation from a priori guess on PCHO-TEPC coagulation & $\Phi_{\mathrm{TEPC}}$ & 1 \\
13) Initial concentration of PON & $f_{\mathrm{PON}}^{\text {ini }}$ & $\mathrm{mmol} \mathrm{N} \mathrm{m}^{-3}$ \\
14) Initial polysaccharide concentration & $f_{\mathrm{PCHO}}^{\text {ini }}$ & $\mathrm{mmol} \mathrm{Cm}^{-3}$ \\
\hline
\end{tabular}

were approximated from other observational studies (e.g. parameters such as minimum and maximum cell quota), Table 1. Among the remaining 14 parameters are those that have not been measured directly, such as the initial phytoplankton biomass concentration, Table 2. These initial concentrations are not a priori prescribed for phytoplankton and heterotrophs, in order to further reduce the bias in our parameter estimates.

Errors of the parameter estimates are determined from 9 additional optimisations with resampled data sets, which substitute the original observations. The measured data are regarded as one realisation, which gives us a total of 10 realisations for the overall analysis. Thus, with this bootstrapping approach we artificially extend our data set to a greater number of realisations based on the presumed information about measurement errors. Gaussian noise was generated and added to the original observational values. The Gaussian noise has a variance $\left(\sigma_{i}^{2}\right)$ identical to the one prescribed for every observation in the cost function. Hence, resampled data remain fully consistent with original observations. For the calculation of parameter uncertainties the approach of Schartau and Oschlies (2003a) is adopted. Here we will not only calculate error variances from all optimisation results $(\sigma \hat{S} D)$, but also give explicit information on the bias. The bias $\left(\hat{\sigma_{B}}\right)$ is given by the deviation of the best parameter estimate ( $\hat{\boldsymbol{p}}_{0}$, according to the lowest cost function of all realisations) from the mean value $(\overline{\boldsymbol{p}})$. Our error estimates include uncertainties of the optimisation algorithm, resulting from differences in convergence when approaching the minimum of the cost function. These uncertainties are inversely proportional to the cost function's sensitivity to parameter variation. An explicit representation of the bias tells us whether our parameter estimates (mean values and standard devia- tions) conform to our prior assumptions of the data-model error distribution and prescribed observational variances. As a consequence, a poor parameter estimate can be identified when the bias is equal, or larger than, the determined standard deviation.

\subsubsection{Optimisation algorithm}

A micro-genetic algorithm ( $\mu \mathrm{GA}$; Krishnakumar, 1989) is used for optimisation. The algorithm was originally programmed and applied by Carroll (1996). In data assimilation studies in the field of marine science this algorithm has been extensively tested (Athias et al., 2000; Schartau, 2001). Stochastic or quasi-stochastic algorithms are recommended for cases where the cost function may contain a variety of local minima or has regions with plane-geometry with a very low sensitivity to parameter changes. Although highest accuracy can be achieved with gradient optimisation techniques (e.g. Vallino, 2000), but they may require a series of individual optimisations in order to find the global minimum solution (Schartau et al., 2001). For this reason, a quasistochastic algorithm, such as the $\mu \mathrm{GA}$, is better suited for our purpose despite the computational advantage of the gradient technique. The $\mu \mathrm{GA}$ applied here assigns a single set of parameters to an individual. This individual is coded as a binary string, similar to genes of a chromosome. A prescribed number of individuals is considered as one generation. Within a generation, the algorithm selects individuals, which become eligible for recombination. Generally the best individuals (e.g. the parameter sets with the lowest cost function values) are selected. After selection, the recombination process (crossover of genes) generates a new generation of individuals (children) of which each one contains information of two 
selected individuals (parents). In addition, elitism principles are expressed by retaining the best individual, passing him from one to the next offspring generation. This elitism operation ensures that the best parameter does not get lost after recombination. If one generation shows less than 5\% difference among all individuals, then a new random population is generated within the prescribed bounds of parameter values. The best individual is saved. This procedure guaranties a convergence characteristic where the full parameter space is repeatedly explored while the algorithm converges towards the lowest point of the cost function. The configuration of the $\mu \mathrm{GA}$ is presented in Table A2 in the Appendix.

\section{Results}

\subsection{Optimal parameter and state estimates}

The proposed model is validated against observational data from a mesocosm experiment. For this reason, optimal model parameter values are determined, which minimise the misfit between model result and data. The misfit is defined as a cost function, Eq. (7). Together with resampled data, which are treated as additional realisations, we performed a total of 10 optimisations. All optimisations converge well to a distinct minimum of the cost function. In all cases, the minimum of the cost function is identified after 35000 iterations. No significant improvements are achieved up to 56000 iterations (14 individuals $\times 4000$ generations), which is the prescribed total number of iterations. Initial cost function values range between $10000<\mathrm{J}<40000$, and the optimisations reduce costs by two orders of magnitude, with solutions that range between $J=256$ and $J=456$. Figure 2 shows the probability distribution (PD) of the outcome of all ten optimisations. According to the $\mathrm{PD}$, the value of expectation for our optimisation problem is approximately $J \approx 290$. This means that any repetition of the optimisation of the same model, but with another resampled data set, must be expected to yield cost function optima close to this value. From the PD we learn that the optimisation problem is well-posed; parameter values and their approximated errors are reproducible estimates. Table 3 shows all parameter estimates together with their errors, and the relative improvements with respect to their initial variational ranges.

Model results exhibit significant variability on an hourly time scale. Such variability remains unresolved in data since all measurements were taken once a day, at times when phytoplankton was exposed to light, Fig. 3. Differences between the ten optimal model state estimates are small, as indicated by the gray shaded envelope of all fitted solutions in Fig. 3 . Similar model trajectories (state estimates) are obtained, although they represent fits to different resampled data. This indicates that the optimisation procedure is robust and that the model setup was chosen appropriately. The proposed parameterisations suffice to simulate the predominant dynamics

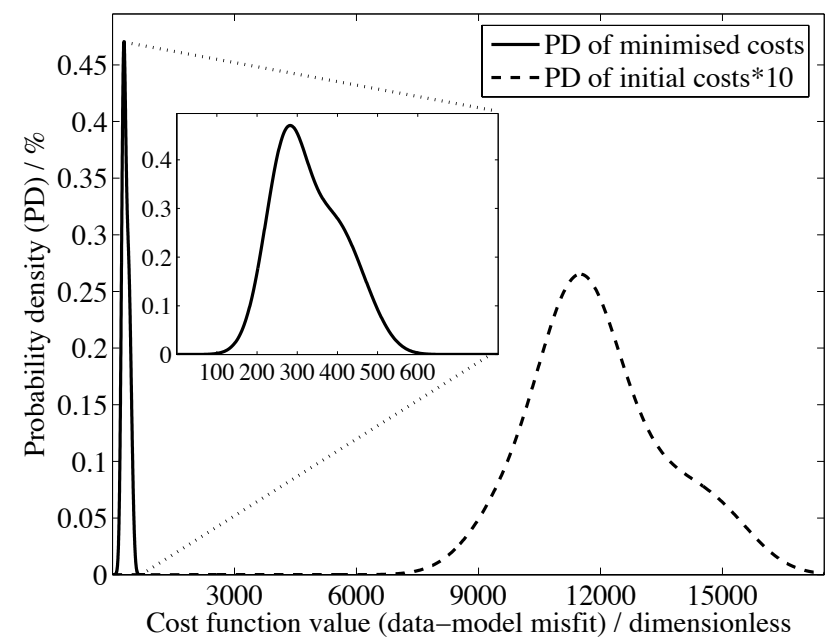

Fig. 2. A priori and a posteriori probability distribution of the datamodel misfits (initial values and minima of cost function J). Repeating the optimisation with any other resampled data will probably yield a minimum of $\mathrm{J}$ in the range shown in the zoomed subplot. Most likely the minimum will be distributed close around $J=280$. The value of expectation is $J=122$, which can only be achieved if the exact moment of sampling was known and if the assumed model equations were free of error.

involved in decoupling the mesocosm's carbon and nitrogen fluxes.

Figures $3 \mathrm{a}$ and $3 \mathrm{~b}$ show the observed and modelled drawdown in DIN and DIC. The modelled uptake of DIC is sensitive to variations of the specific rate parameter for maximum photosynthesis $\left(\mu_{C}\right)$. Our estimate of $\mu_{C}=2.4 \pm 0.6 \mathrm{~d}^{-1}$ falls within the typical observational range and thereby hardly differs from those values that are generally observed under different laboratory- or mesocosm conditions (e.g. Geider et al., 1998). In contrast to purely nitrogen-based models, photosynthesis continues at times when phytoplankton growth is DIN limited. Thus, DIC concentrations further decrease although nitrogen uptake has ceased.

The modelled DIN uptake is somewhat slower than the increase in Chla concentration, when comparing Figs. 3a and 3c. Better model fits for the observed DIN drawdown cause a greater data-model mismatch in Chla concentration. This mismatch is associated with the purely nitrogen-based parameterisation of Chla synthesis in the model, described in the discussion section. In spite of the systematic offset, the optimisation procedure finds a compromise solution between DIN uptake and Chl $a$ synthesis. The dates of DIN depletion and maximum Chla concentration between days 15 and 16 are resolved well by the model. The maximum Chla concentration is reached shortly after DIN becomes depleted, Fig. 3c.

During the decrease in Chla concentration, the model maintains a constant concentration of PON, Fig. 3d, which is primarily caused by the transformation of algal biomass 
Table 3. Parameter estimates after optimisation: The standard deviations $\widehat{\sigma}_{\text {std }}$ are approximated from bootstrapping. The bias $\left(\sigma_{\text {bias }}\right)$ is derived from the deviation of the best parameter estimate $\left(\widehat{\mathbf{p}}_{\text {best }}\right)$ from the mean parameter value $(\overline{\mathbf{p}})$. The last column relates the standard deviation to the prior variational range of parameter values $(\triangle \mathbf{p})$.

\begin{tabular}{llccccc}
\hline Parameter & Unit & $\widehat{\mathbf{p}}_{\text {best }}$ & $\overline{\mathbf{p}}$ & $\widehat{\sigma}_{\text {std }}$ & $\sigma_{\text {bias }}=\widehat{\mathbf{p}}_{\text {best }}-\overline{\mathbf{p}}$ & $\widehat{\sigma}_{\text {std }} / \Delta \mathbf{p}$ \\
\hline 1) $\mu_{C}$ & $\mathrm{~d}^{-1}$ & 2.300 & 2.370 & 0.629 & -0.070 & 0.10 \\
2) $\gamma_{N}$ & $\mathrm{~d}^{-1}$ & 0.180 & 0.153 & 0.079 & 0.027 & 0.13 \\
3) $\gamma_{C}$ & $\mathrm{~d}^{-1}$ & 0.250 & 0.293 & 0.166 & -0.043 & 0.26 \\
4) $\rho_{N}$ & $\mathrm{~d}^{-1}$ & 0.240 & 0.210 & 0.119 & 0.030 & 0.31 \\
5) $\rho_{C}$ & $\mathrm{~d}^{-1}$ & 0.372 & 0.202 & 0.184 & 0.170 & 0.48 \\
6) $\Phi_{P D}$ & 1 & 0.000 & 0.030 & 0.048 & -0.030 & $<0.01$ \\
7) $\omega_{N}$ & $\mathrm{~d}^{-1}$ & 0.018 & 0.033 & 0.024 & -0.015 & 0.39 \\
8) $\omega_{C}$ & $\mathrm{~d}^{-1}$ & 0.004 & 0.018 & 0.019 & -0.014 & 0.31 \\
9) $g_{m}$ & $\mathrm{~d}^{-1}$ & 0.230 & 0.176 & 0.096 & 0.054 & 0.15 \\
10) $f_{\text {PCHO }}$ & 1 & 0.640 & 0.634 & 0.201 & 0.006 & 0.20 \\
11) $\Phi_{\text {PCHO }}$ & 1 & 2.000 & 1.190 & 1.199 & 0.810 & 0.10 \\
12) $\Phi_{\text {TEPC }}$ & 1 & 0.500 & 0.550 & 0.237 & -0.050 & 0.02 \\
13) $f_{\text {PON }}^{\text {ini }}$ & $\mathrm{mmol} \mathrm{N} \mathrm{m}^{-3}$ & 0.800 & 1.095 & 0.659 & -0.295 & 0.05 \\
14) $f_{\text {PCHO }}^{\text {ini }}$ & $\mathrm{mmol} \mathrm{m}^{-3}$ & 4.000 & 4.050 & 3.000 & -0.050 & 0.02 \\
\hline
\end{tabular}

into detrital material and a simultaneous rapid degradation of Chla. In our model the aggregation of cells is regarded as a transformation of phytoplankton biomass into detritus. This transformation is adequately approximated by the quadratic term given in Eq. (B12). According to our optimisation, the more elaborate parameterisation of Ruiz et al. (2002) is found to be insignificant for explaining the data. This is stressed by estimates of the dimensionless factor that is multiplied with the aggregation parameterisation $\left(\Phi_{P D}=0.03 \pm 0.05\right)$. The parameter $\Phi_{P D}$ describes the deviation from our a priori assumption on aggregation. The equation of Ruiz et al. (2002), describing the coagulation of large detrital particles (marine snow) with phytoplankton cells, does not support model solutions that are in agreement with our entire data set. Optimal model solutions suggest that all detrital material during the experiment must have remained small in size. It can be explained by the gentle but constant stirring within the tank that seems to have significantly hindered the formation of larger marine snow despite the tremendous accumulation of biomass. We learned that estimates for phytoplankton aggregation strongly depend on the experimental setup of the mesocosm study. Indeed, measurements of size spectra are expected to provide the only reasonable constraint for validating parameterisations of phytoplankton aggregation.

Photo-autotrophic conditions prevail and heterotrophic activity in the optimised model solutions is small. In contrast to the transformation of algal biomass into detrital material, the phytoplankton loss to herbivores, and thus to the heterotrophic pool, has only a minor impact on the Chla drawdown in the model. We obtain a small rate constant for the nitrogen specific loss rate, e.g. a maximum rate of $g_{m}=0.18 \pm 0.1 \mathrm{~d}^{-1}$. From preliminary studies we found that a model closure, containing a separate compartment for het- erotrophs, is needed to improve fits to gross primary production and net community production. Both rate measurements are crucial constraints for determining the degree of heterotrophic activity during the mesocosm experiment. However, at the end of the simulation period (day 19 through 22), model results show the tendency to either overestimate heterotrophic conditions or to underestimate carbon overconsumption. Given the constraints, we are not able to determine the deficiency that prevails. Both possible scenarios cause elevated DIC and lowered POC concentrations, Figs. $3 \mathrm{~b}$ and $4 a$.

A key element of the model is the linkage between carbon assimilation by phytoplankton, loss of organic matter that replenishes the labile DOM pool, and the subsequent formation of TEPC from DOC. Besides reasonable estimates for photosynthesis and DIN uptake, we also find highly resolved rate constants for describing phytoplankton release of organic nitrogen and carbon $\left(\gamma_{N}=0.15 \pm 0.08 \mathrm{~d}^{-1}\right.$ and $\left.\gamma_{C}=0.29 \pm 0.17 \mathrm{~d}^{-1}\right)$. Standard deviation and bias remain small for both parameters. The carbon release rate is significantly larger than the organic nitrogen loss by phytoplankton. This stresses the importance of assigning distinct rates for nitrogen and carbon losses. The amount of organic carbon released by phytoplankton largely depends on two factors: the photosynthetic rate and on the existing phytoplankton biomass respectively. In our study both factors are well constrained by DIC and Chla data, together with PON observations.

With our data-assimilative approach we are able to indirectly determine the amount of $\mathrm{PCHO}$ exudation as a fraction of the overall DOC release by phytoplankton. The optimisation yields results where the PCHO fraction of total exuded organic carbon is close to $63 \%\left(\mathrm{f}_{\mathrm{PCHO}}=0.63 \pm 0.20\right)$. This is 

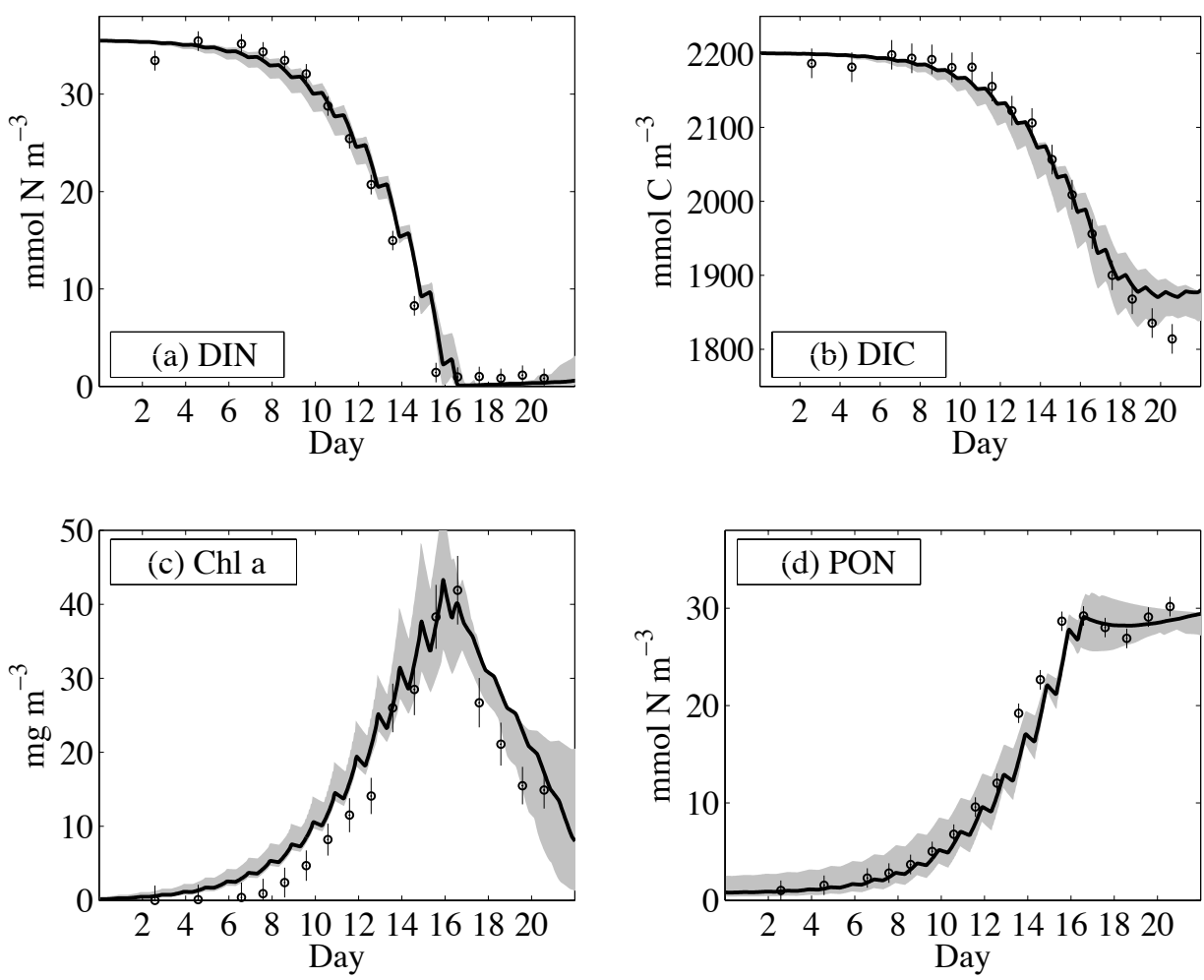

Fig. 3. Optimised model results. All solid black lines indicate the best solution obtained from optimisation with the original data set. Circles represent observations together with their corresponding error standard deviations, as assigned for the weighting of the cost function. The gray shaded area enfolds all model trajectories obtained from the additional optimisations performed with resampled data, see text for details. The upper panel shows (a) dissolved inorganic nitrogen (DIN) and (b) the carbon counterpart, dissolved inorganic carbon (DIC). The lower panel displays (c) chlorophyll concentration (Chla) and (d) particulate organic nitrogen (PON).

a substantial fraction, suggesting that the vast majority of exuded carbon can become subject to coagulation and can thus be transformed into extracellular POC. Modelled POM concentrations reveal only small variations among the ten model runs, as indicated by the shaded area in Figs. $3 \mathrm{~d}$ and $4 \mathrm{a}$. The decoupling between PON and POC formation becomes expressed during DIN depletion around day 16, coinciding with the initial decrease in Chla. Uncertainties in modelled PON and POC remain less than $10 \%$ during nitrogen-limited conditions. Significantly lower POC concentrations are obtained if TEPC was omitted, and if a constant $\mathrm{C}: \mathrm{N}$ conversion factor of 6.625 was multiplied with the modelled PON. As a consequence, the high POC concentration can only be explained by the carbon content of TEP, Fig. 4b, in combination with detrital carbon and phytoplankton biomass.

In Engel et al. (2004) the parameters describing the interaction between PCHO and TEP were determined on the basis of an individual data set obtained during a mesocosm bloom experiment with the coccolithophore Emiliania huxleyi. In this study we adopt their initial parameter estimates. However, in order to test the use of these parameter estimates for a more general situation, we define two dimensionless factors ( $\Phi_{\mathrm{PCHO}}$ and $\Phi_{\mathrm{TEPC}}$ ) that describe deviations of our parameter optimisation from the prior assumption. In this way, we directly relate our new optimal guesses to the parameter values determined in Engel et al. (2004). Because of the absence of explicit PCHO data for this mesocosm experiment, we find the product of attachment probability and collision kernel for PCHO-TEPC coagulation better constrained than the PCHO-PCHO interaction $\left(\widehat{\sigma}_{\Phi_{\mathrm{PCHO}}}>\widehat{\sigma}_{\Phi_{\mathrm{TEPC}}}\right)$. The parameter uncertainty in $\mathrm{PCHO}-\mathrm{PCHO}$ coagulation thus directly translates into uncertainties in PCHO state estimates, Fig. 4c. Despite of the described uncertainty, the mean value for PCHO$\mathrm{PCHO}$ coagulation is in agreement with the values proposed in Engel et al. (2004).

A significant deviation from the a priori estimate is identified for TEPC-PCHO coagulation. The model produces its best fit to the TEPC data when coagulation rates are half of those assumed a priori $\left(\Phi_{\mathrm{TEPC}}=0.55 \pm 0.24\right)$. Note that this estimate refers to a product of two parameters. We cannot specify how the $55 \%$ deviation is distributed between attachment probability and collision kernel. Although our optimal values for TEPC-PCHO coagulation are 55\% smaller than presumed, the modelled transition of PCHO to TEPC still depends primarily on the TEP concentration that has already been formed. This model result agrees with observations, showing no significant TEPC formation before day 10 of the experiment. Once a sufficient amount of TEP has formed, 

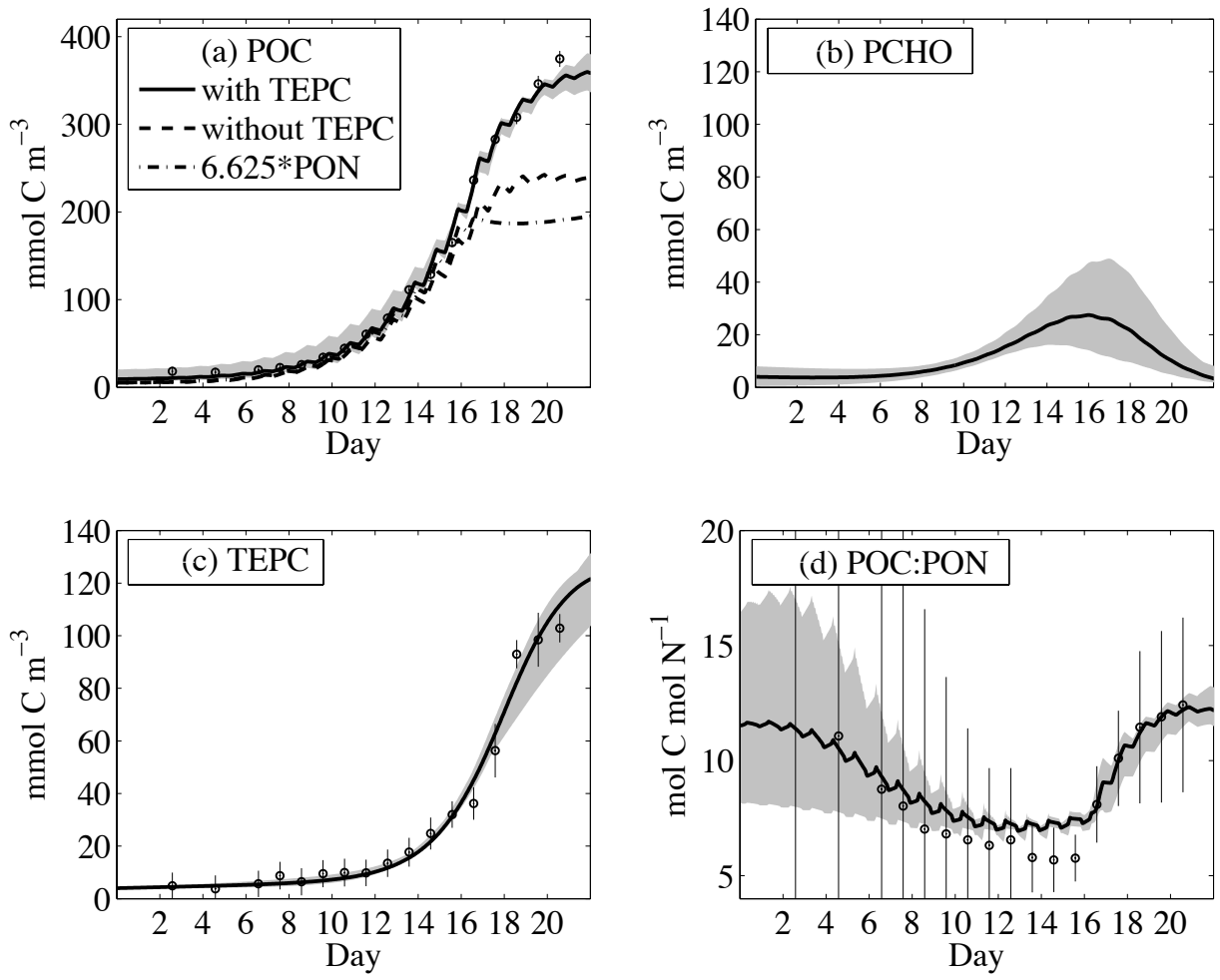

Fig. 4. Optimised model results of particulate organic matter and polysaccharides (PCHO). The upper left panel (a) resolves particulate organic carbon (POC) as it is regarded in the model, but also as it would be derived from cellular carbon and from PON with a constant molar carbon-to-nitrogen $(\mathrm{C}: \mathrm{N})$ ratio of 6.625. (b) PCHO is the precursor of the carbon found in (c) transparent exopolymeric particles (TEPC). All TEP in the model is given in carbon units (TEPC) and is assigned to the POC pool. (d) Modelled C:N ratio of particulate organic matter (POC:PON) increases rapidly after day 16 when phytoplankton production becomes nitrogen limited. The large uncertainties are associated with the division of small biomass concentrations.

larger particles capture smaller particles more rapidly, which eventually initiates the distinct increase in TEPC concentration. It is at this transitional phase of accelerated TEP formation where we also find the largest uncertainties in modelled PCHO concentration, Fig. 4c.

The POC:PON ratio remains above Redfield under DIN replete conditions, Fig. 4d. This is solely caused by optimal estimates for PON ( $f_{P O N}$ ), while measured TEPC concentration is used as initial condition. TEPC enters our POC pool, which results in elevated POC:PON ratios for low concentrations in plankton biomass. Luxury consumption of nitrogen is simulated during DIN replete conditions, indicated by a $\mathrm{C}: \mathrm{N}$ assimilation ratio for phytoplankton that varies between 5.8 and 6.2 depending on light exposure. Observational and model errors in POC:PON ratio at the beginning of the experiment follow from the division of small biomass concentrations. We find diel variations in POC:PON ratio, as a consequence of variable light-dark conditions. DIN is continuously taken up in the model, including the dark time periods. Around day 16, the POC:PON ratio rapidly increases from values around 7 to a maximum of 12 at day 22 .

A fraction $(37 \%)$ of the total DOC release replenishes the residual DOC pool (resDOC) in the model. All dis- solved organic carbon that is not specified as $\mathrm{PCHO}$ is assigned to this compartment. Interestingly, our model results show how concentrations in resDOC can vary between 19 to $85 \mathrm{mmol} \mathrm{C} \mathrm{m}^{-3}$ without altering TEPC concentration. It suggests that a portion of total DOC can, in principle, fuel microbial activity while TEPC formation happens simultaneously. Two major sinks for DOC removal can exist in parallel. Variations in resDOC and DON in Fig. 5 result from uncertainties in linear remineralisation rates $\left(\rho_{N}=0.21 \pm 0.12\right.$ and $\rho_{C}=0.20 \pm 0.18$ ). Moreover, our estimation of the carbon remineralisation rate for resDOC is hardly improved with our optimisation, if compared with the initial range of variation, Table 3. Similar to the remineralisation rates for DOM, the estimates for degradation and remineralisation of detritus remain uncertain $\left(\omega_{N}=0.03 \pm 0.02 \mathrm{~d}^{-1}\right.$ and $\left.\omega_{C}=0.02 \pm 0.02 \mathrm{~d}^{-1}\right)$. However, our estimates show that the rate of detritus degradation must have been one order of magnitude smaller than the direct mineralisation of DOM. Thus, heterotrophic activity in the model is sustained by DOM mineralisation. A sensitivity analysis (results not shown) reveals that the estimates of DOM mineralisation support phytoplankton growth during the nitrate- depleted phase and prevent a more drastic drawdown in phytoplankton biomass. 

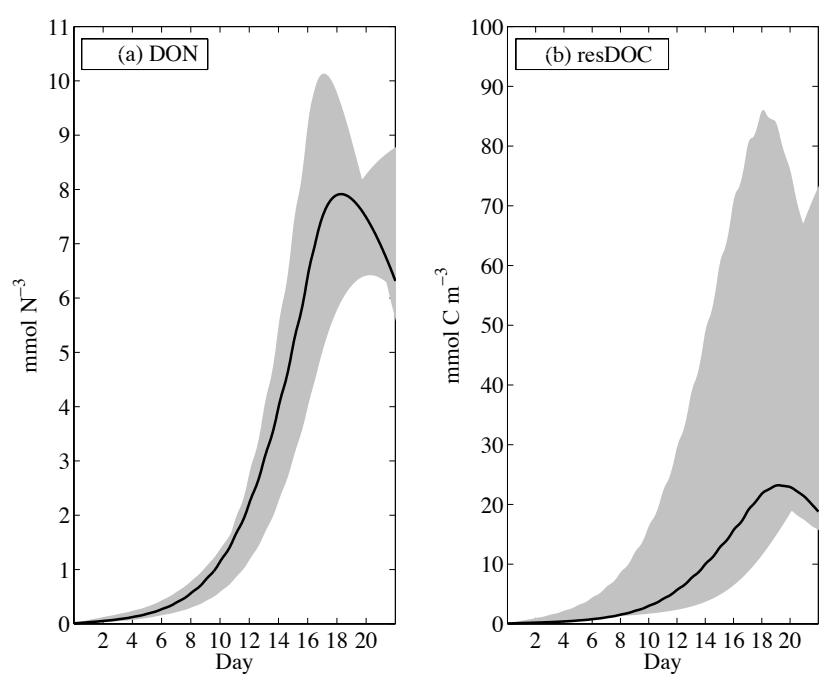

Fig. 5. Modelled dissolved organic matter that is not associated with PCHO or TEP. DON is well constrained whereas resDOC shows largest variations of all model state variables. The best model solution is biased with a much higher remineralisation rate for resDOC $\left(\rho_{C}=0.37 \mathrm{~d}^{-1}\right)$ than for DON $\left(\rho_{N}=0.24 \mathrm{~d}^{-1}\right)$, whereas the mean rate estimates are similar $\left(\overline{\rho_{C}} \approx \overline{\rho_{N}}=0.2 \mathrm{~d}^{-1}\right)$.

Our optimal estimate of the DON turnover is largely constrained by the standing stock measurements of PON and Chl $a$ during the post-bloom period (day 15 through 19).

Primary productivity in the mesocosm was determined from measured oxygen utilisation rates, which allows the distinction to be made between gross- and net community production rates. In the model, total carbon assimilation by phytoplankton is the counterpart to observed gross primary production (GPP). Whereas modelled net community production (NCP) is set equal to the carbon assimilation minus respiration of phytoplankton and heterotrophs, and minus remineralisation of resDOC, Fig. 6. The consideration of NCP data for parameter optimisation turned out to be essential for constraining the dominant carbon and nitrogen closures in the model. Uncertainties in modelled productivity are comparable to observational errors. The best model trajectory of GPP matches measurements well. Observed NCP rates show large fluctuations. Model results underestimate $\mathrm{NCP}$ at the beginning of the experiment, but eventually become consistent with maximum rates at days 15 and 16. In general, the data-model comparison of productivity indicates that net phytoplankton growth and respiration are well resolved, thereby supporting a reliable rate estimate of PCHO exudation.

According to our model results, carbon overconsumption can be split up into two dominant modes. In the absence of luxury nitrogen consumption, all carbon assimilated by phytoplankton leads to an accumulation of carbon in biomass and a concomitant increase in DOC. Biomass accumulation in phytoplankton continues as long as growth exceeds all
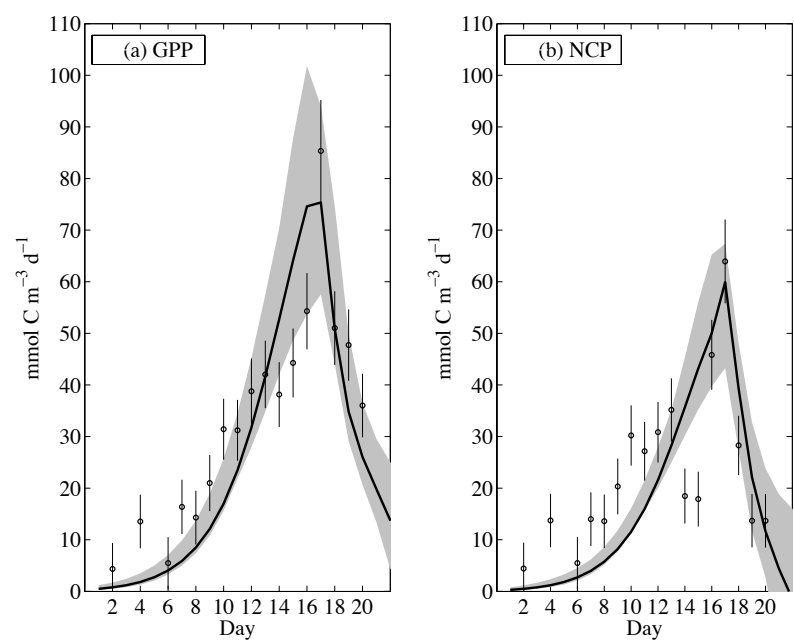

Fig. 6. Modelled phytoplankton productivity. Gross primary production (GPP) remains high during an efficient three days growth period, from day 13 to day 16 . Net community production (NCP) accounts for all net carbon uptake by phytoplankton minus community respiration.

losses due to grazing by herbivores or particle aggregation. During this phase of new production, the released organic carbon remains linearly linked to the nitrogen loss by phytoplankton, Fig. 7a. The linearity may already allow for a carbon exudation that exceeds the nitrogen loss multiplied by a carbon-to-nitrogen ratio of $\mathrm{C}: \mathrm{N}=6.625$ (compare black with gray lines in Fig. 7a). Any excess in organic carbon exudation above Redfield during growth can be interpreted as the first mode of carbon overconsumption. The second mode is associated with an excessive carbon release by phytoplankton under nutrient limited conditions, at times when no biomass accumulates further. Figure $7 \mathrm{~b}$ shows organic carbon exudation relative to DIN assimilation by phytoplankton (DOC exudation normalized to DIN uptake). The plot demonstrates how the increase in carbon loss during the first mode results from phytoplankton biomass accumulation, as indicated by a constant value of carbon loss per $\mathrm{N}$-uptake. The correlation between $\mathrm{N}$ and $\mathrm{C}$ loss by phytoplankton lapses when new production has ceased. A decline in phytoplankton biomass initiated by nutrient limitation is associated with a maximum release of organic carbon (maximum carbon overconsumption). If the proceeding growth phase allows a noticeable accumulation of PCHO (during mode one), then a significant portion of overconsumed carbon is likely to be rapidly transformed into POC (during mode two), which is eventually exported with fast sinking particle aggregates. 

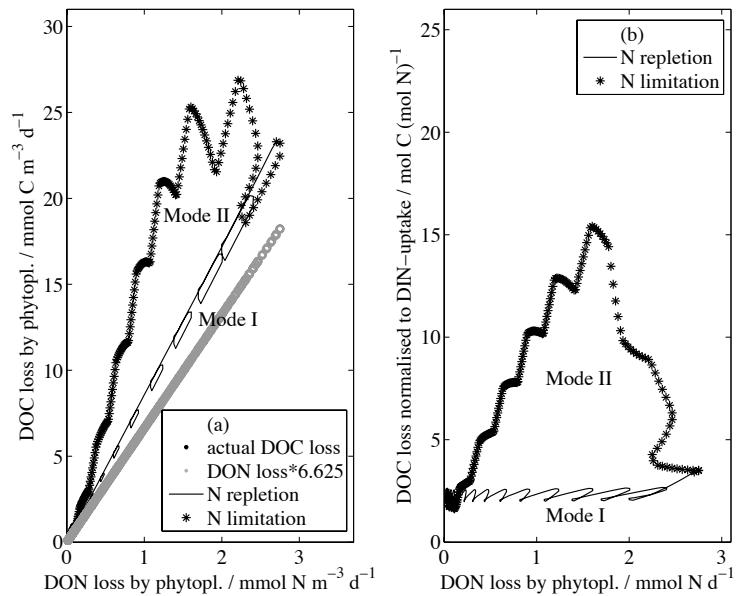

Fig. 7. DOM losses by phytoplankton: (a) DOC exudation in relation to DON loss by phytoplankton; (b) specific DOC loss (normalised to DIN uptake) in relation to DON loss. The two modes of carbon overconsumption are depicted. DOC and DON losses during the growth phase ( $\mathrm{N}$ repletion) are linear functions of biomass accumulation. During post-bloom conditions ( $\mathrm{N}$ limitation) the release of DOC by phytoplankton depends on photosynthetic rates and thus on DIC uptake.

\section{Sensitivity analyses}

\subsection{Variation of initial DIN concentration}

The model's sensitivity to variations of parameter values can be directly deduced from Figs. 3-6. In addition, we performed a sensitivity analysis, where the initial DIN concentration has been varied between 5 and $50 \mathrm{mmol} \mathrm{N} \mathrm{m}^{-3}$. Varying initial DIN concentrations can be interpreted by analogy to winter DIN concentrations for different ocean regions. DIN concentrations between 1 and $20 \mathrm{mmol} \mathrm{N} \mathrm{m}^{-3}$ simulate open ocean winter concentrations whereas higher values are more representative for coastal waters. In Fig. 8 we find a persistent pattern of DOC exudation versus DON loss, where the two modes of DOM production described above are consistently well-defined. With initial concentrations of $\mathrm{DIN}_{0}=5 \mathrm{mmol} \mathrm{m}^{-3}$ the modelled maximum exudation rate of DOC becomes approximately $6 \mathrm{mmol} \mathrm{C} \mathrm{m}^{-3} \mathrm{~d}^{-1}$ whereas a rate of $30 \mathrm{mmol} \mathrm{C} \mathrm{m}^{-3} \mathrm{~d}^{-1}$ is reached for $\mathrm{DIN}_{0}=50 \mathrm{mmol} \mathrm{m}^{-3}$. Modelled DOC exudation normalised to DIN assimilation by phytoplankton exhibit a ratio around $2.3 \mathrm{~mol} \mathrm{C}(\mathrm{mol} \mathrm{N})^{-1}$ under nutrient replete conditions that is invariant with changes in initial DIN concentration (as in Fig. 7b).

As we consider two modes for carbon overconsumption we will also find two modes if we relate Chl $a$ to TEPC concentration. In Fig. 9, a linear relationship exists between Chl $a$ increase and the build up of TEPC during the growth phase, at times when PCHO exudation is linearly linked with biomass accumulation. We find a nonlinear response in the

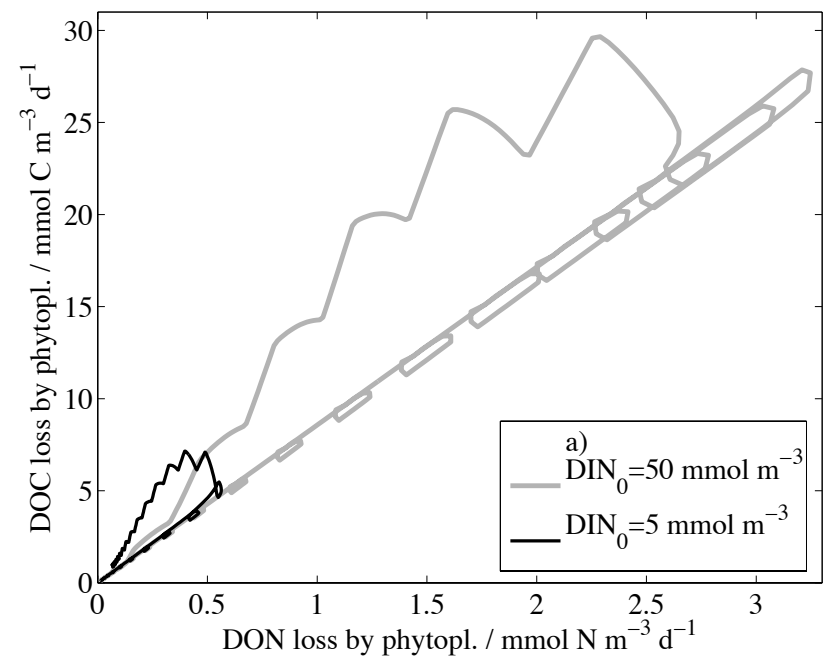

Fig. 8. DOC exudation in relation to DON loss by phytoplankton. The initial concentration of DIN $\left(\mathrm{DIN}_{0}\right)$ has been varied between 5 and $50 \mathrm{mmol} \mathrm{m}^{-3}$. Model solutions are based on our best parameter estimate. During the growth phase (N-replete conditions) the daily mean DOC exudation is linearly linked to DON loss by phytoplankton. Diurnal variations (loops) during mode one result from variations in carbon-to-nitrogen uptake ratio. According to this model version, the initial DIN concentration only determines the total amount of biomass accumulation an thus the maximum DOC loss rate during the growth phase.

TEPC:Chla ratio during the post-bloom period, which we did not specify. The concurrence of the rapid increase in TEPC concentration during a phase of massive Chla degradation causes large uncertainties for deriving TEPC from Chl $a$. Our sensitivity study indicates that a reasonable TEPC:Chla ratio for the post-bloom period can be derived if the amount of new production was known together with the maximum Chla concentration.

4.2 Quantitative and qualitative variation of DOC released by phytoplankton

The current model version does not distinguish between leakage and exudation of DOM. Small molecular DOM is expected to passively pass the membrane of an algae (Bjørnsen, 1988). Larger molecules, such as PCHO, have to be actively transported through the membrane. By means of data assimilation we obtain an estimate of the PCHO fraction of total DOC release. But for our first estimate, we have assumed a constant fraction. It means that the model's PCHO exudation rate remains proportional to phytoplankton biomass. In order to assess the validity of this simplistic parameterisation we perform a sensitivity analysis with subsequent optimisations. We first assimilate data from the growth phase and then use data from the post-bloom period. Based on our results of the preceding optimisation, we re-estimate those four parameter values that are relevant for total DOC release and TEP formation, listed in Table 4. 
Table 4. Variation of parameter estimates if separated between growth phase and post-bloom period. Standard deviations $\left(\widehat{\sigma}_{\text {std }}\right)$ are approximated from bootstrapping.

\begin{tabular}{llccc}
\hline Parameter & Unit & $\begin{array}{c}\text { entire period } \\
\overline{\mathbf{p}} \pm \widehat{\sigma}_{\text {std }}\end{array}$ & $\begin{array}{c}\text { initial \& bloom phase } \\
\overline{\mathbf{p}} \pm \widehat{\sigma}_{\text {std }}\end{array}$ & $\begin{array}{c}\text { post-bloom period } \\
\overline{\mathbf{p}} \pm \widehat{\sigma}_{\text {std }}\end{array}$ \\
\hline$\gamma_{C}$ & $\mathrm{~d}^{-1}$ & $0.29 \pm 0.17$ & $0.24 \pm 0.01$ & $0.25 \pm 0.01$ \\
$f_{\mathrm{PCHO}}$ & 1 & $0.63 \pm 0.20$ & $0.34 \pm 0.08$ & $0.63 \pm 0.10$ \\
$\Phi_{\mathrm{PCHO}}$ & 1 & $1.19 \pm 1.20$ & $3.67 \pm 2.67$ & $0.99 \pm 1.07$ \\
$\Phi_{\mathrm{TEPC}}$ & 1 & $0.55 \pm 0.24$ & $1.07 \pm 0.23$ & $0.56 \pm 0.05$ \\
\hline
\end{tabular}

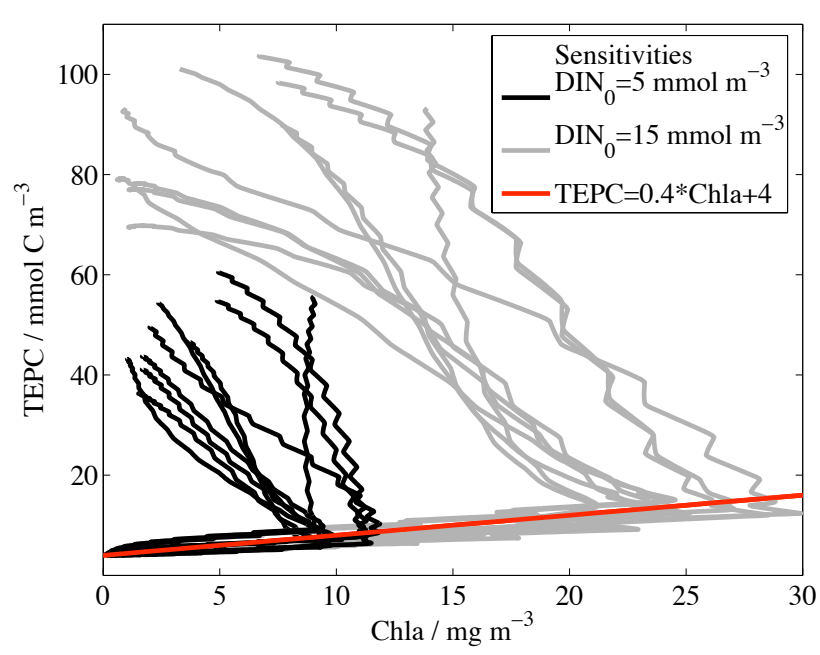

Fig. 9. Results of a sensitivity analysis: The initial concentration of DIN $\left(\mathrm{DIN}_{0}\right)$ has been varied between 1 and $15 \mathrm{mmol} \mathrm{m}^{-3}$. The two modes of carbon overconsumption translate into two modes of TEPC formation. During phytoplankton growth the model shows a linear dependence between TEPC formation and Chl $a$ increase. During the post-bloom period, degradation of Chla falls together with the distinct increase in TEPC concentration.

The posterior cost function distribution of the preceding optimisations (with the full data set) is compared with the joint distribution of the separated optimisations (by adding together the minimum costs of growth- and post-bloom phase respectively), Fig. 10a. We do not find significantly better model performance compared to the preceding runs. Thus, if we had implemented separate process descriptions for exudation of PCHO and for the release of residual DOC, we must expect that such apparent improvement does not automatically translate into a significant reduction of the misfit between data and model result. However, if we had additional data on $\mathrm{PCHO}$ and resDOC entering our cost function we would probably be able to constrain such separation between biomass proportional leakage and physiologically regulated exudation. In the vicinity of the preceding parameter estimates we find no indication for temporal variations in total DOC release rate but can clearly identify a significant change in the PCHO fraction of that release, Fig. $10 \mathrm{~b}$.

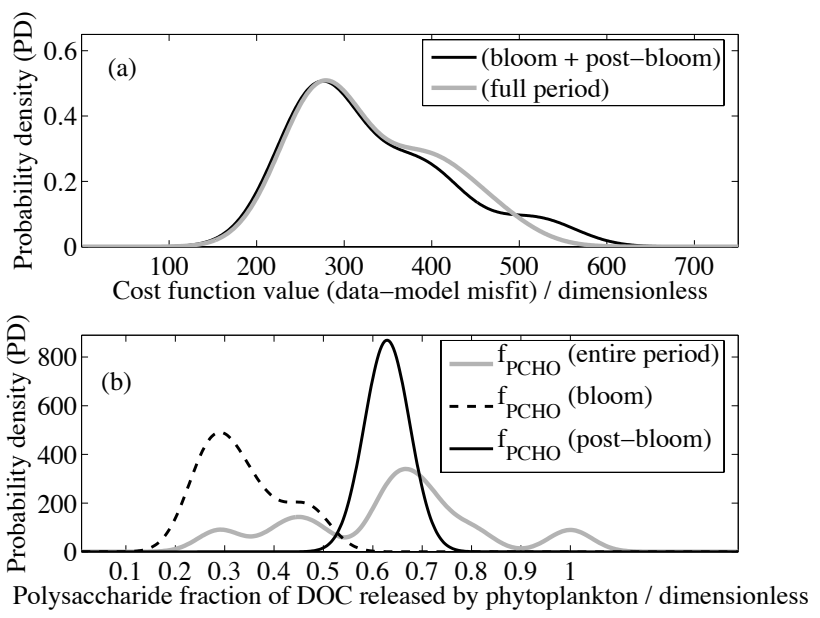

Fig. 10. Results of subsequent optimisations: Partial data has been assimilated into the model, distinguishing between bloom and postbloom period respectively. (a) The posterior distribution of the sum of the two cost function values obtained from the separated periods reveal similar costs compared to the optimised model where all parameters remain constant over the entire period. (b) The PCHO fraction $\left(\mathrm{f}_{\mathrm{PCHO}}\right)$ of DOC released by phytoplankton changes from $30 \%$ during the growth phase to $63 \%$ during the post-bloom period.

The fraction of $\mathrm{PCHO}$ is about $34 \pm 8 \%$ during the growth phase, whereas we find a twofold increase, up to $63 \pm 12 \%$ in the post-bloom period. Thus, the proportionality assumption does hold for the total release of DOC but model refinements are needed with respect to qualitative changes, such as a variations in release of PCHO. Our results indicate that the PCHO-PCHO aggregation is negatively correlated with the fraction of PCHO released (more efficient coagulation with smaller PCHO fraction of DOC released). These results point towards the necessity of using explicit PCHO data for improved estimates. Given a model that resolves variable $\mathrm{C}: \mathrm{N}$ ratios in phytoplankton biomass (e.g. due to acclimation), the sensitivity study reveals qualitative changes in DOC released by phytoplankton, but refinements with respect to a more sophisticated, non-biomass proportional, release rate for bulk DOC will hardly upgrade the model's fit to data. 


\section{Discussion}

A clear distinction must be made between primary produced biomass and POM that is formed from extracellular DOM. This differentiation becomes particularly relevant when biogenic changes in carbon budgets are investigated on the basis of nitrogen or phosphorus fluxes, because of differences in stoichiometry (C:N:P ratio). So far, overconsumed carbon and an excessive DOC exudation was accounted for only in few modelling studies (e.g. Anderson and Williams, 1998, 1999; Van den Meersche et al., 2004), but TEP formation has been largely neglected. Observational studies, however, clearly demonstrated the relevance of TEPC production for correctly assessing organic carbon fluxes (e.g. Mari et al., 2001; Engel and Passow, 2001). A basic modelling approach was presented by Mari and Burd (1998). They applied a sizeclass model to explain observed TEP concentrations. Their model approach, focused on the coagulation process, with TEP given in units of volume concentration. The rather descriptive character of TEP measurements made biogeochemical modellers disregard it. This arose out of the situation that TEP is generally measured either microscopically or colorimetrically as stained particles (Passow, 2002), which does not provide a direct quantitative measure in carbon or nitrogen units. Although the potential role of TEP for the biological pump has been discussed before, many questions on how it can mediate oceanic carbon fluxes remain unanswered.

A qualitative connection between DOC exudation, TEPC formation and the export of marine snow (aggregates of POC) is now better understood (e.g. Jackson, 1998; Engel et al., 2004). It is the connection between carbon overconsumption with TEPC formation that attracts our attention. In a global, biogeochemical steady-state model, sensitivities in the biological pump are determined while varying POC:PON export ratios (Schneider et al., 2004). In their study, they assumed a $\mathrm{CO}_{2}$ sensitive TEPC formation that instantly translates into an elevated POC:PON export ratio when atmospheric $\mathrm{CO}_{2}$ rise. They found a considerable increase in carbon export for small variations in the $\mathrm{C}: \mathrm{N}$ elemental ratio of POM. Their model is based on a steady-state assumption, which limits the applicability of their model. In reality the variability in TEPC concentrations is high in space and time and largely depends on the seasonal dynamics of gross primary production and the actual accumulation of phytoplankton biomass. The model described here is capable of simulating a cascade from DIC uptake, through DOC exudation to TEPC formation while resolving associated nitrogen fluxes. It has been shown that the formulated link between carbon overconsumption and extracellular POC formation is reasonable and that the model provides a good starting point and tool for biogeochemical simulations.

\subsection{Modelling limitations}

The model applied here includes simplified parameterisations of complex biological processes. From a biogeochemical point of view, any decision on whether an additional zooplankton or bacteria compartment is needed in order to better match observed POC and Chla concentrations, has to be well justified and must not distract from other substantial problems, such as modelling extracellular POC formation (a source for POC and a sink for DOC). If a single important process is neglected, the associated bias can mask benefits that are achieved elsewhere in the model, for example by having a mechanistic description of bacterial utilisation of DOM. Among marine biologists the decoupling of nitrogen from carbon utilisation by phytoplankton is already a well established physiological attribute (e.g. Smetacek and Pollehne, 1986). But only during the last decade, biogeochemical modellers started to appreciate biological models with variable carbon-to- nitrogen or carbon-to-phosphorus stoichiometry (e.g. Doney et al., 2002; Hood et al., 2006). Also, variable stoichiometric assimilation ratios should be coherent with the synthesis of Chla. We applied the parameterisation of Geider et al. (1998), where Chla synthesis is directly coupled to nitrogen utilisation of the phytoplankton. By no means were we able to exactly simulate the observed DIN drawdown together with the rise in Chla concentration. In the model we find high nitrogen uptake rates during dark conditions of the light cycle, at times with a minimum in carbon assimilation and photosynthesis. The modelled Chla synthesis clearly overestimates the observed increase in concentration. This is a model deficiency, which leads to a systematic error, although small. More elaborate descriptions for modelling Chla synthesis account for an optimal allocation of carbon within the cell, in order to either further increase the crosssection for light absorption (high Chla:C ratio) or to invest more into cellular growth (Pahlow, 2005, R. Armstrong, personal communication). It is worthwhile modifying and testing our model version with the parameterisation suggested by Pahlow (2005).

Our simplistic first approximation is to assume DOMrelease by phytoplankton to be proportional to its biomass. Apart from surface to volume relationships, this assumption holds for small molecular DOM (Bjørnsen, 1988). Our prior knowledge, however, about PCHO is that they are unlikely to passively pass through an algal membrane and must therefore be actively transported to the exterior of the cell, called exudation or excretion. Yet, mechanisms that relate active versus passive release of carbon and nitrogen from phytoplankton are not well understood. Previous modelling studies achieved better agreement with DOC data when DOC release is assumed to depend on the normalised difference between saturated growth and actual growth conditions, (Anderson and Williams, 1998). The phytoplankton model compartment in Anderson and Williams (1998) was described in nitrogen units and did not include acclimation dynamics. 
Thus, for the DOC release they had to assume a constant $\mathrm{C}: \mathrm{N}$ ratio. Their growth dependence (given in nitrogen units) for DOC exudation was then superior to a biomass proportional approach. This model improvement in DOC release can also be interpreted in that it simulates an increase in the $\mathrm{C}: \mathrm{N}$ ratio within the phytoplankton compartment, while promoting DOC exudation. In spite of the reasonability of their approach, a release rate of DOC being proportional to phytoplankton biomass given in carbon units has not been falsified. In Van den Meersche et al. (2004) the ideas of Anderson and Williams (1998) are directly adopted but applied to an ecosystem model with acclimation and variable stoichiometry of phytoplankton. The results of our sensitivity analysis suggest to first concentrate on quality changes of DOC released by phytoplankton rather than seeking for parameterisations that separate biomass proportional leakage from the regulated, and possibly highly non-linear, process of active exudation. Eventually, it will be the knowledge about qualitative changes of DOC released by phytoplankton that is likely to guide improved model parameterisations on exudation.

The present model includes a crude closure for grazing and remineralisation. For simulations of the mesocosm experiment, the simple closures suffice to account for the little heterotrophic activity observed during the experiment. Under more realistic oceanic conditions, a separate model compartment for bacteria can be regarded. A potential difficulty in constraining a separate bacteria compartment must be expected, if TEPC formation is regarded as an additional sink for DOC, other than mineralisation. Grazing by microzooplankton is oversimplified in the model and certainly needs refinement when attempting to simulate seasonal cycles in the ocean. The aggregation parameterisation remains unconstrained and a true assessment of the equations proposed by Ruiz et al. (2002) is lacking for realistic oceanic conditions. A more detailed validation study is therefore desired, in particular since TEPC formation interacts with phytoplankton aggregation. Alternative formulations for sizebased marine snow formation were proposed (e.g. Kriest and Evans, 1999). A model assessment of different approaches to simulate marine snow formation would be helpful. Overall, upgrading the mesocosm model setup to a more generic model version, which can be used for large-scale simulations, is feasible. For this, one can choose from the variety of proposed and published biogeochemical closures.

\subsection{Modelling primary production: what does it mean?}

For prognostic studies in marine biogeochemistry, the assimilation of primary production data into ecosystem models is substantial since it often provides the only flux constraint besides much more uncertain sediment trap observations. A difficult task, however, is to specify the correct modelcounterpart to observed primary production rates, especially if data of ${ }^{14} \mathrm{C}$-incubation measurements are used for data as- similation experiments (e.g. Evans, 1999; Spitz et al., 2001; Schartau and Oschlies, 2003b). Concerning ${ }^{14} \mathrm{C}$-incubations measurements the answers remain controversial (e.g. Banse, 2002; Marra, 2003). Whether measured rates are closer to gross- than to net production is still unclear. For example, the possibility of $\mathrm{TEP}^{14} \mathrm{C}$ formation affecting measured $\mathrm{PO}^{14} \mathrm{C}$ production has not been discussed yet.

Our optimal estimate of the PCHO fraction of exuded DOC is close to $64 \pm 20 \%$. It stresses how a major part of the freshly exuded DOC (which is a significant fraction of the gross production) can form colloidal particles that become large enough to be retained on filters used for the quantification of POC. We find carbon exudation rates that are higher than the loss of DON, which suggests that from DON alone it is difficult to directly infer an accumulation of labile DOC. This clarification, allowing one to better distinguish between net and gross primary production, will help modellers in assessing their simulation results. If net primary production is simply understood as the transformation of DIC to POC, and given that extracellular POC formation happens, then all nitrogen- or phosphorus based ecosystemmodels are biased. Such bias seems negligible in regions where little primary produced biomass accumulates (e.g. in oligotrophic provinces). In eutrophic regions, on the other hand, most carbon will be transferred through higher trophic levels before being exported and phytoplankton biomass will be top-down controlled. A bias is likely to become significant in temperate waters, if ecological conditions allow a substantial phytoplankton biomass accumulation before either nitrogen or phosphorus becomes depleted. The postbloom period would then be the typical timeframe for systematic data- model misfits in primary production, if TEPC formation were disregarded. Regions with iron limitation are a possible exception, because photosynthetic rates, DIC uptake and thus DOC exudation are limited there.

\subsection{Linkage between carbon overconsumption, particle for- mation and export}

Many biogeochemical modelling studies refer to the concept of new production, calculated from the phytoplankton's uptake of freshly entrained nitrate within the upper ocean's light-lit layers (Dugdale and Goering, 1967). If nitrogen fixation and atmospheric nitrogen inputs are negligible, this new production must equal the vertical export of organic matter because of mass conservation (Eppley and Peterson, 1979). Whether this assumption is appropriate for deriving marine carbon cycles solely from nitrogen or phosphorus fluxes is questionable. Our model approach provides a link from phytoplankton growth and its variable stoichiometry to TEPC formation. Modelling the source of TEP (preferentially given in carbon units rather than xanthan gum equivalents) will subsequently improve the modelling of marine snow formation (Passow et al., 1994; Logan et al., 1995; Passow, 2002). For example, in the presence of TEP the 
overall coagulation rate is not only affected by increasing total effective particle concentration but also by enhancing the probability of two particles sticking together after collision (Jackson, 1998; Engel, 2000). Resolving physiological acclimation of phytoplankton and accounting for the origin and fate of freshly exuded organic matter will likely alter simulations of biogenic carbon export.

Imbalances between nitrogen uptake and carbon based primary production are often explained with local biological processes, such as DON utilisation by phytoplankton or nitrogen fixation. Furthermore, excessive DIC uptake during apparent $\mathrm{N}$ or $\mathrm{P}$ depletion is believed to locally accumulate in DOC. But to identify conditions for carbon overconsumption is not straightforward and must not be confused with purely physical reasons that cause local excessive DIC drawdown. For example, Michaels et al. (1994) noted carbon imbalances near Bermuda at the site of the Bermuda Atlantic Time series Study (BATS). At the BATS site the measured excess DIC drawdown can be explained largely by a southward advection of water masses from regions with higher biological productivity. But a local, non-advective biological effect appears to be important as well (Toggweiler, 1994). The time derivative of DIC was analysed and Toggweiler (1994) found the fastest drawdown of DIC during May, at a time when oceanographic conditions are identified to have a minimum effect on DIC changes. A biological contribution to the overall carbon imbalance must be expected and it becomes maximal at a time when nitrate concentrations have just run below the detection limit.

Our study supports the idea of Anderson and Pondaven (2003) that biology does provide a significant contribution to carbon overconsumption, with carbon being channelled through the DOC pool. However, we propose not to omit alternative sinks for DOC other than bacterial degradation. In our model solution a large fraction of phytoplankton carbon overconsumption goes into TEPC and the smaller portion accumulate as residual, labile DOC. The model sensitivity study shows that several factors control TEPC formation. At oligotrophic sites the accumulation of phytoplankton biomass remains low while bacteria have relative high abundance (e.g. around $0.3 \mathrm{mmol} \mathrm{N} \mathrm{m}^{-3}$ at the BATS site). Therefore all fresh DOC is likely to be consumed. If we reduce the initial concentration of DIN in our model from $35 \mathrm{mmol} \mathrm{N} \mathrm{m}^{-3}$ to $1 \mathrm{mmol} \mathrm{N} \mathrm{m}^{-3}$ (comparable with maximum possible surface concentrations near Bermuda), the TEPC concentration reaches no more than $15 \mathrm{mmol} \mathrm{C} \mathrm{m}^{-3}$ at day 22. To what extent such low TEPC concentration can contribute to POC export is unclear. A relationship between carbon overconsumption and POC export will depend on the amount of biomass accumulation that promotes the second mode of carbon overconsumption, as shown in our sensitivity study.

In the paper of Wells (1998) the importance of marine colloids and their aggregation to form larger particles was stressed. His discussion primarily referred to the findings of Chin et al. (1998), who investigated the transformation of dissolved organic substances to form large, sinking conglomerates. They used ideas of polymer gel theory to interpret the colloidal formation dynamics in terms of a self-assembling process. The term "self-assembly" is rather broad and applies to spontaneous aggregation and formation of ordered structures when pre-existing components (separate or distinct parts of a disordered structure) are mixed in correct proportions (Evans and Wennerström, 1999). The process is reversible and involves systems that are at thermodynamic equilibrium. "Self-assembly" is thus not synonymous with formation of structures during an irreversible growth process proceeding in a steady state away from the thermodynamic equilibrium. For a kinetic growth process, such as coagulation, the components must be able to move with respect to one another. If the components attach irreversible when they collide, they form fractal-like aggregates (Mari and Burd, 1998) rather than regular structures, which are formed by self-assembly. Nevertheless, coagulation of preexisting components can involve self-assembling processes. This can be the case if components are able to equilibrate between aggregated and non-aggregated states, or to adjust their positions relative to one another in the space of an aggregate. Both spontaneous self-assembly (Chin et al., 1998) and particle coagulation (e.g. Mari and Burd, 1998) have been proposed for the mechanism of formation of TEP. Chin et al. (1998) demonstrated the formation of self-assembled nano-aggregates under laboratory conditions. However, the particle size spectra and the fractal geometry of TEP observed in more natural environment suggest a kinetic growth process, where TEP is formed via coagulation of either individual polysaccharides or small-sized, self-assembled precursors.

\section{Conclusions}

A simple model is proposed for simulating carbon overconsumption in conjunction with TEPC formation. Our comparison of simulation results with data from a mesocosm experiment demonstrates how the model fits the rapid increase in TEPC concentration shortly after nitrate assimilation has ceased, while associated nitrogen fluxes are resolved. This study suggests that the cascade from DIC uptake, through DOC exudation to TEPC formation can be described with simple parameterisations, by combining dynamical equations for algal growth with a model of extracellular PCHO-PCHO and PCHO-TEPC aggregation. The formulated link between carbon overconsumption and extracellular POC formation is reasonable and the model provides a starting point for subsequent biogeochemical simulations.

In this study, the optimised parameters describing the PCHO-TEP dynamics are consistent with the parameters derived from data from a different independent experiment with coccolithophores Engel et al. (2004). This suggests that two 
size classes are sufficient to describe the complex coagulation process involved in TEP formation. This simple parameterisation of PCHO coagulation is useful to take into account the PCHO-TEP dynamics into higher-scale ecosystem models.

According to our simulations of the mesocosm experiment, carbon overconsumption is split up into two dominant modes. Any excess in organic carbon exudation above Redfield during the growth phase can be interpreted as the first mode of carbon overconsumption. The second mode causes an excessive carbon release by phytoplankton under nutrient limited conditions. During the first mode of carbon overconsumption, the release of DOC by phytoplankton is linearly linked to the loss of DON. The exudation of labile DOC during the second mode exhibits a nonlinear relationship with the loss of DON. The total amount of exuded DOC depends on the phytoplankton biomass that could accumulate during the growth phase.

Our data-assimilative approach demonstrates how an adequate model can be used for estimating rate parameters that could not be measured during an experiment. With a bootstrapping approach we generated synthetic data that are consistent with observations. The synthetic data sets are regarded as additional realisations of the experiment in order to estimate errors of the optimal parameter values. We conclude that this primitive approximation suffices to determine the robustness of our optimal estimates. Thus, a repetition of the optimisation, for example with another synthetically resampled data set but with the same model, is expected to produce estimates that fall within the range of uncertainties listed here.

\section{Appendix A}

\section{Carbon and Nitrogen Regulated Ecosystem Model (CN-REcoM)}

Parameterisations for phytoplankton growth are mainly adopted from Geider et al. (1998). One minor modification in modelling phytoplankton growth has been done for the cell quota step function $\left(R_{C}^{N}\right)$, which regulates $\mathrm{N}$ acquisition down when the maximum cellular $\mathrm{N}: \mathrm{C}$ ratio is reached. The modelled closure for mass fluxes includes heterotrophic activity. The heterotrophic compartment combines bacteria and herbivorous microplankton. Biogeochemical mass fluxes within the simplified ecosystem are primarily regulated by the nitrogen-to-carbon (N:C) quota of phytoplankton, as well as by $\mathrm{C}$ and $\mathrm{N}$ specific rates for respiration, remineralisation, and degradation of organic matter. Therefore, we simply refer to the following set of equations as Carbon and NitrogenRegulated Ecosystem Model (CN-REcoM). In the following, the model's sources minus sinks (sms) equations for nitrogen and carbon fluxes are listed.
A1 Dissolved inorganic compounds

DIC sms=net carbon uptake by phytoplankton + heterotrophic maintenance respiration + remineralisation of residual dissolved organic carbon (resDOC) + carbon dioxide $\mathrm{CO}_{2}$ air-water exchange $\left(F_{C}\right)$ :

$$
\begin{aligned}
\mathrm{DIC}_{t} & =\left(r_{\text {phy }}-C_{\text {phot }}\right) \cdot \text { PhyC }+r_{\text {het }} \cdot \text { HetC } \\
& +\rho_{C} \cdot T_{f} \cdot \text { resDOC }+F_{C}
\end{aligned}
$$

Initial condition: $\mathrm{DIC}_{0}=2200 \mathrm{mmol} \mathrm{C} \mathrm{m}^{-3}$.

DIN sms = nitrogen utilisation by phytoplankton + remineralisation of dissolved organic nitrogen (DON):

$\operatorname{DIN}_{t}=-\frac{V_{C}^{N}}{q} \cdot$ PhyN $+\rho_{N} \cdot T_{f} \cdot \mathrm{DON}$

Initial condition: $\mathrm{DIN}_{0}=35.5 \mathrm{mmol} \mathrm{N} \mathrm{m}^{-3}$.

Total alkalinity (TA) sms $=\mathrm{N}$ and $\mathrm{P}$ uptake by phytoplankton $-\mathrm{N}$ and $\mathrm{P}$ remineralisation:

$$
\begin{aligned}
\mathrm{TA}_{t} & =(1+1 / 16) \cdot\left(\frac{V_{C}^{N}}{q}\right) \cdot \text { PhyN } \\
& -(1+1 / 16) \cdot \rho_{N} \cdot T_{f} \cdot \mathrm{DON}
\end{aligned}
$$

Initial condition: $\mathrm{TA}_{0}=2440 \mathrm{mmol} \mathrm{m}^{-3}$. Concentrations of ammonia were small $\left(<0.5 \mathrm{mmol} \mathrm{N} \mathrm{m}^{-3}\right)$. Therefore, the effect of ammonia on TA (TA decreases by one mole per mol ammonia taken up) is neglected.

\section{A2 Phytoplankton}

Phytoplankton carbon sms $=$ Photosynthesis - respiration - exudation/leakage - aggregation of phytoplankton cells grazing/lysis:

$\mathrm{PhyC}_{t}=\left(C_{\text {phot }}-r_{\text {phy }}-\gamma_{C}\right) \cdot$ PhyC $-\frac{(A+G)}{q}$

Initial condition: $\mathrm{PhyC}_{0}=\mathrm{PhyN}_{0}$. Redfield.

Phytoplankton nitrogen sms $=\mathrm{N}$-uptake - leakage - aggregation of phytoplankton cells - grazing/lysis:

$\operatorname{PhyN}_{t}=\left(\frac{V_{C}^{N}}{q}-\gamma_{N}\right) \cdot \operatorname{PhyN}-(A+G)$

Initial condition: $\mathrm{PhyN}_{0}=0.1 \cdot f_{\mathrm{PON}}^{\mathrm{ini}}$, see parameters for optimisation.

Phytoplankton Chl $a$ sms = Chl $a$ synthesis - decay - aggregation of phytoplankton cells - grazing/lysis:

$\operatorname{Chl} a_{t}=\left(S_{\mathrm{chl}}-\gamma_{\mathrm{chl}}\right) \cdot \operatorname{Chl} a-\frac{\theta_{C}}{q} \cdot(A+G)$

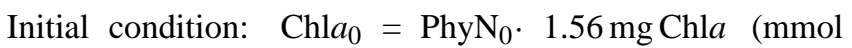
$\mathrm{N})^{-1}$. 
Table A1. Observational error variances $\left(\sigma_{i}^{2}\right)$ assigned to the cost function. Some variances $\left(\hat{\sigma}_{\mathrm{obs}}^{2}\right)$ are derived from triplicate samples of the mesocosm experiment. For Chl $a$, gross primary production (GPP), and net community production (NCP) an uncertainty proportional to the measured value is added to as background error.

\begin{tabular}{ll}
\hline Type of observation & Assigned observational errors \\
\hline 1) DIN & $1^{2}+\hat{\sigma}_{\mathrm{obs}}^{2}(\mathrm{mmol} \mathrm{N})^{2} \mathrm{~m}^{-6}$ \\
2) DIC & $10^{2}(\mathrm{mmol} \mathrm{C})^{2} \mathrm{~m}^{-6}$ \\
3) Chl $a$ & $2^{2}+(0.1 \cdot \mathrm{Chl} a \mathrm{obs})^{2} \mathrm{mg}^{2} \mathrm{~m}^{-6}$ \\
4) PON & $1^{2}+\hat{\sigma}_{\mathrm{obs}}^{2}(\mathrm{mmol} \mathrm{N})^{2} \mathrm{~m}^{-6}$ \\
5) POC & $5^{2}+\hat{\sigma}_{\mathrm{obs}}^{2}(\mathrm{mmol} \mathrm{C})^{2} \mathrm{~m}^{-6}$ \\
6) TEPC & $1^{2}+\hat{\sigma}_{\mathrm{obs}}^{2}(\mathrm{mmol} \mathrm{C})^{2} \mathrm{~m}^{-6}$ \\
7) GPP & $5^{2}+\left(0.1 \cdot \mathrm{GPP}_{\mathrm{obs}}\right)^{2}\left(\mathrm{mmol} \mathrm{C}^{2} \mathrm{~m}^{-6} \mathrm{~d}^{-2}\right.$ \\
8) NCP & $5^{2}+\left(0.1 \cdot \mathrm{NCP}_{\mathrm{obs}}\right)^{2}(\mathrm{mmol} \mathrm{C})^{2} \mathrm{~m}^{-6} \mathrm{~d}^{-2}$ \\
\hline
\end{tabular}

A3 Heterotrophs (microzooplankton+bacteria)

Heterotrophs carbon sms $=$ grazing/lysis - maintenance respiration - carbon loss closure:

$\mathrm{HetC}_{t}=\frac{G}{q}-\left(r_{\text {het }}+\gamma_{\text {het }}\right) \mathrm{HetC}$

Initial condition: $\mathrm{HetC}_{0}=\mathrm{HetN}_{0} \cdot$ Redfield.

Heterotrophs nitrogen $\mathrm{sms}=$ grazing/lysis - nitrogen loss closure:

$\operatorname{HetN}_{t}=G-\gamma_{\text {het }} \cdot \operatorname{HetN}$

Initial condition: $\operatorname{HetN}_{0}=0.45 \cdot f_{\mathrm{PON}}^{\text {ini }}$.

\section{A4 Detritus}

Detritus carbon sms = aggregation of phytoplankton cells breakdown of detrital carbon:

$\operatorname{DetC}_{t}=\frac{A}{q}-\omega_{C} \cdot T_{f} \cdot \operatorname{DetC}$

Initial condition: $\operatorname{DetC}_{0}=\operatorname{DetN}_{0} \cdot$ Redfield.

Detritus nitrogen sms = aggregation of phytoplankton cells breakdown of detrital nitrogen:

$\operatorname{DetN}_{t}=A-\omega_{N} \cdot T_{f} \cdot \operatorname{DetN}$

Initial condition: $\operatorname{Det} \mathrm{N}_{0}=0.45 \cdot f_{\mathrm{PON}}^{\mathrm{ini}}$, see parameters for optimisation.

\section{A5 Dissolved organic compounds}

Residual dissolved organic carbon sms = exudation/leakage of residual organic carbon + breakdown of detrital carbon
+ degradation of transparent exopolymer particles (TEPC) remineralisation:

$$
\begin{aligned}
\operatorname{resDOC}_{t} & =\gamma_{C} \cdot\left(1-f_{\mathrm{PCHO}}\right) \cdot \mathrm{PhyC}+\gamma_{\text {het }} \cdot \text { HetC } \\
& +\omega_{C} \cdot T_{f} \cdot \operatorname{DetC}+\rho_{*}^{C} \cdot T_{f} \cdot \mathrm{TEPC} \\
& -\rho_{C} \cdot T_{f} \cdot \operatorname{resDOC}
\end{aligned}
$$

Initial condition: resDOC $_{0}=\mathrm{DON}_{0} \cdot$ Redfield.

Dissolved organic nitrogen sms $=$ exudation/leakage of organic nitrogen by phytoplankton + breakdown of detrital nitrogen - remineralisation:

$$
\begin{aligned}
\text { DON }_{t} & =\gamma_{N} \cdot \text { PhyN }+\gamma_{\text {het }} \cdot \text { HetN } \\
& +\omega_{N} \cdot T_{f} \cdot \operatorname{DetN}-\rho_{N} \cdot T_{f} \cdot \text { DON }
\end{aligned}
$$

Initial condition: $\mathrm{DON}_{0}=0.01 \mathrm{mmol} \mathrm{N} \mathrm{m}^{-3}$.

Polysaccharides sms $=$ exudation by phytoplankton - aggre gation with other PCHO particles - aggregation of PCHO with transparent exopolymeric particles (TEPC):

$$
\begin{aligned}
\mathrm{PCHO}_{t} & =\gamma_{C} \cdot f_{\mathrm{PCHO}} \cdot \mathrm{PhyC} \\
& -\Phi_{\mathrm{PCHO}} \cdot \alpha_{\mathrm{PCHO}} \beta_{\mathrm{PCHO}} \cdot \mathrm{PCHO}^{2} \\
& -\Phi_{\mathrm{TEP}} \cdot \alpha_{\mathrm{TEPC}} \beta_{\mathrm{TEPC}} \cdot \mathrm{PCHO} \cdot \mathrm{TEPC}
\end{aligned}
$$

Initial condition: $\mathrm{PCHO}_{0}=f_{\mathrm{PCHO}}^{\mathrm{ini}}$, see parameters for optimisation.

\section{A6 Transparent exopolymer particles}

Carbon content of transparent exopolymer particles sms = aggregation with other small PCHO + aggregation of small PCHO with larger TEPC - degradation of TEPC (breakdown to resDOC):

$$
\begin{aligned}
\mathrm{TEPC}_{t} & =\Phi_{\mathrm{PCHO}} \cdot \alpha_{\mathrm{PCHO}} \beta_{\mathrm{PCHO}} \cdot \mathrm{PCHO}^{2} \\
& +\Phi_{\mathrm{TEPC}} \cdot \alpha_{\mathrm{TEPC}} \beta_{\mathrm{TEPC}} \cdot \mathrm{PCHO} \cdot \mathrm{TEPC} \\
& -\rho_{*}^{C} \cdot T_{f} \cdot \mathrm{TEPC}
\end{aligned}
$$

Initial condition: $\mathrm{TEPC}_{0}=4.0 \mathrm{mmol} \mathrm{C} \mathrm{m}^{-3}$.

\section{Appendix B}

\section{Details}

B1 Arrhenius relation for describing temperature dependence

$T_{f}=\exp \left[-A_{E} \cdot\left(\frac{1}{T}-\frac{1}{T_{\text {ref }}}\right)\right]$

During the mesocosm experiment the mean temperature was $285.15^{\circ}$ Kelvin $\left(12^{\circ} \mathrm{C}\right)$, yielding a constant factor for all temperature dependent rates of $T_{f} \approx 0.85$. 
Table A2. Setting for the $\mu \mathrm{GA}$. Each parameter is represented by a discrete binary string of a certain length. One individual combines all strings of all parameters (one parameter set). The number of possibilities expresses the number of binary digits that describes the number of possible values within the prescribed upper and lower limits for parameter variation.

\begin{tabular}{llrr}
\hline No.\& Symbol & Variational range $[\mathrm{min} / \mathrm{max}]$ & Increment & No. of possibilities \\
\hline 1) $\mu_{C}$ & $0.100 / 6.400$ & 0.1 & 64 \\
2) $\gamma_{N}$ & $0.010 / 0.640$ & 0.01 & 64 \\
3) $\gamma_{C}$ & $0.010 / 0.640$ & 0.005 & 64 \\
4) $\rho_{N}$ & $0.003 / 0.384$ & 0.003 & 128 \\
5) $\rho_{C}$ & $0.003 / 0.384$ & 0.003 & 128 \\
6) $\Phi_{P D}$ & $0.000 / 12.700$ & 0.1 & 128 \\
7) $\omega_{N}$ & $0.002 / 0.064$ & 0.002 & 32 \\
8) $\omega_{C}$ & $0.002 / 0.064$ & 0.01 & 32 \\
9) $g_{m}$ & $0.0000 / 0.630$ & 0.01 & 64 \\
10) $f_{\mathrm{PCHO}}$ & $0.0000 / \mathrm{min}(1.0,1.27)$ & 0.01 & 128 \\
11) $\Phi^{\mathrm{PCHO}}$ & $0.100 / 12.800$ & 0.1 & 128 \\
12) $\Phi^{\mathrm{TEPC}}$ & $0.100 / 12.800$ & 0.1 & 128 \\
13) $f_{\mathrm{PON}}^{\text {ini }}$ & $0.050 / 12.800$ & 0.05 & 256 \\
14) $f_{\mathrm{PCHO}}^{\text {ini }}$ & $0.500 / 128.000$ & 0.5 & 256 \\
\hline
\end{tabular}

B2 Carbon assimilation and respiration of phytoplankton

$C_{\text {Phot }}=\mu_{C}^{\max } \cdot\left[1-\exp \left(-\frac{\theta_{C} \cdot \alpha \cdot I}{\mu_{C}^{\max }}\right)\right]$

The maximum rate of carbon-specific photosynthesis is regulated by temperature and the cell quota:

$\mu_{C}^{\max }=\mu_{C} \cdot R_{\mathrm{Phot}} \cdot T_{f}$

Regulation as a function of the cellular nitrogen-to-carbon ratio (q)

$R_{\mathrm{Phot}}=\frac{\left(q-q_{\mathrm{min}}\right)}{\left(q_{\max }-q_{\min }\right)}$

with the phytoplankton's actual nitrogen-to-carbon ratio ( $\mathrm{q}=\mathrm{N}: \mathrm{C}$ quota), together with the prescribed minimum and maximum quotas $\left(q_{\min }\right.$ and $\left.q_{\max }\right)$.

Phytoplankton respiration is the sum of biosynthetic costs and the maintenance metabolic rate:

$r_{\text {phy }}=r_{C}+\zeta \cdot V_{C}^{N}$

B3 Nitrogen assimilation

$V_{C}^{N}=\mu_{C}^{\max } \cdot q_{\max } \cdot R_{C}^{N} \cdot \frac{\mathrm{DIN}}{\mathrm{DIN}+k_{N}}$

The maximum rate of carbon-specific nitrate uptake is controlled by the cell quota and related to the maximum rate of photosynthesis. The regulation function depends on the cellular nitrogen-to-carbon ratio:

$R_{C}^{N}=1-\exp \left[-\sigma_{C}^{N} \cdot\left(\left|q-q_{\max }\right|-\left(q-q_{\max }\right)\right)^{2}\right]$

with the slope parameter $\left(\sigma_{C}^{N}\right)$ and the maximum cellular nitrogen-to-carbon ratio $\left(q_{\max }\right)$.

B4 Chla synthesis

$S_{\mathrm{Chl}}=\frac{V_{C}^{N}}{\theta_{C}} \cdot R_{\mathrm{Chl}}$

The regulation is a function of maximum chlorophyll a-tonitrogen ratio and light (energy) utilisation, according to Geider et al. (1998):

$R_{\mathrm{Chl}}=\theta_{N}^{\max }\left(\frac{C_{\mathrm{Phot}}}{\theta_{C} \cdot \alpha_{\mathrm{Chl}} \cdot I}\right)$

B5 Grazing/general loss to heterotrophs

$G=g_{m} \cdot \frac{\text { PhyN }^{2}}{\epsilon+\mathrm{PhyN}^{2}} \cdot \operatorname{HetN}$

The search activity of herbivores is enhanced when prey density (PhyN) increases. It describes the functional response of a Holling Type III function. 
B6 Heterotrophic respiration

$r_{\text {het }}=\max \left(0.01, \tau_{\text {het }} \cdot T_{f} \cdot\left(q_{\text {het }}^{-1}-\right.\right.$ Redfield $\left.)\right)$

with respiration relaxing towards the Redfield $\mathrm{C}: \mathrm{N}$ ratio. For $q_{\text {het }}^{-1} \leq$ Redfield, the respiration reduces to $0.01 \mathrm{~d}^{-1}$. Thus, the heterotrophs are assumed to respire more carbon when the food source, phytoplankton, becomes rich in carbon (phytoplankton with low quota q).

\section{B7 Aggregation of phytoplankton cells}

$A=\Phi_{P P} \cdot \mathrm{PhyN}^{2}+\Phi_{P D} \cdot \beta \cdot \mathrm{PhyN} \cdot \operatorname{DetN}$

Aggregation is determined by a quadratic loss of phytoplankton (interaction among small phytoplankton cells) and a product of phytoplankton with detrital biomass. The latter is parameterized with a coagulation kernel, which describes the interaction between large detrital aggregates and small individual phytoplankton cells. The coagulation $\operatorname{kernel}(\beta)$ is controlled by particle stickiness, which partially depends on the amount of TEPC produced. For this model version we adopt the approach described in Ruiz et al. (2002):

$$
\begin{aligned}
\beta & =\frac{2.736 l\left(\mathrm{mg} \mathrm{C}^{-1} \mathrm{~d}^{-1} \cdot 12(\mathrm{mg} \mathrm{C})(\mathrm{mmol} \mathrm{C})^{-1}\right.}{q \cdot 10001 \mathrm{~m}^{-3}} \\
& \cdot \frac{\text { TEPC }}{k_{\beta}+\text { TEPC }} \\
& =0.033 \mathrm{~m}^{3}\left(\mathrm{mmol} \mathrm{N}^{-1} \mathrm{~d}^{-1} \cdot \frac{\text { TEPC }}{k_{\beta}+\text { TEPC }}\right.
\end{aligned}
$$

The conversion factor of Engel and Passow (2001) is applied to convert stained TEP to carbon units (TEPC)

$\mathrm{TEPC}=0.75\left(\frac{(\mathrm{mg} \mathrm{C}) \mathrm{m}^{-3}}{\mu \mathrm{g} \text { Xan. equiv. } \mathrm{L}^{-1}}\right) \cdot \mathrm{TEP}$

Thus, the half-saturation constant according to Ruiz et al. (2002) can be expressed in carbon units. It then becomes

$k_{\beta}=53.125 \mathrm{mmol} \mathrm{C} \mathrm{m}^{-3}$

The parameter $\Phi_{\mathrm{PD}}$ is a dimensionless factor for optimisation (Table 2 and Table A3). It simply expresses the uncertainty of our a priori assumptions for phytoplankton aggregation (Eqs. B12-B15).

Edited by: J. Middelburg

\section{References}

Anderson, T. and Pondaven, P.: Non-redfield carbon and nitrogen cycling in the Sargasso Sea: Pelagic imbalances and export flux, Deep-Sea Res. I, 50(5), 573-591, 2003.

Anderson, T. and Williams, P. B.: Modelling the Seasonal Cycle of Dissolved Organic Carbon at Station E1 in the English Channel, Estuarine, Coastal Shelf Sci., 46, 93-109, 1998.
Anderson, T. and Williams, P. B.: A one-dimensional model of dissolved organic carbon cycling in the water column incorporating combined biological-photochemical decomposition, Global Biogeochem. Cycles, 13(2), 337-349, 1999.

Athias, V., Mazzega, P., and Jeandel, C.: Selecting a global optimization method to estimate the oceanic particle cycling rate constants, J. Mar. Res., 58, 675-707, 2000.

Banse, K.: Uptake of inorganic carbon and nitrate by marine plankton and the Redfield ratio, Global Biogeochem. Cycles, 4, 81-84, 1994.

Banse, K.: Should we continue to measure ${ }^{14} \mathrm{C}$-uptake by phytoplankton for another 50 years?, Limnol. Oceanogr. Bull., 11, 4546, 2002.

Bjørnsen, P. K.: Phytoplankton exudation of organic matter: Why do healthy cells do it?, Limnol. Oceanogr., 33, 151-154, 1988.

Broström, G.: A note on the $\mathrm{C} / \mathrm{N}$ and $\mathrm{C} / \mathrm{P}$ ratio of the biological production in the Nordic Seas, Tellus, 50B, 93-109, 1998.

Carlson, C. A., Ducklow, H. W., Hansell, D. A., and Smith, W. O.: Organic carbon partitioning during spring phytoplankton blooms in the Ross Sea polynya and the Sargasso Sea, Limnol. Oceanogr., 43(3), 375-386, 1998.

Carroll, D. L.: Genetic algorithms and optimizing chemical oxygeniodine lasers, Developments in Theoretical and Applied Mechanics, 18, 411-424, 1996.

Chin, W.-C., Orellana, M., and Verdugo, P.: Spontaneous assembly of marine dissolved organic matter into polymer gels, Nature, 391, 568-572, 1998.

Doney, S. C., Kleypas, J., Sarmiento, J., and Falkowski, P.: The US JGOFS Synthesis and Modeling Project - An Introduction, Deep-Sea Res. II, 49, 1-20, 2002.

Dugdale, R. and Goering, J.: Uptake of new and regenerated forms of nitrogen in primary productivity, Limnol. Oceanogr., 12, 196206, 1967.

Engel, A.: The role of transparent exopolymer particles (TEP) in the increase in apparent particle stickiness during the decline of a diatom bloom., J. Plankton Res., 22, 485-497, 2000.

Engel, A. and Passow, U.: Carbon and nitrogen content of transparent exopolymer particles (TEP) in relation to their Alcian Blue adsorption., Mar. Ecol. Prog. Ser., 219, 1-10, 2001.

Engel, A., Goldthwait, S., Passow, U., and Alldredge, A.: Temporal decoupling of carbon and nitrogen dynamics in a mesocosm diatom bloom, Limnol. Oceanogr., 47(3), 753-761, 2002.

Engel, A., Thoms, S., Riebesell, U., Rochelle-Newall, E., and Zondervan, I.: Polysaccharide aggregation as a potential sink of marine dissolved organic carbon, Nature, 428, 929-932, 2004.

Eppley, R. W. and Peterson, B.: Particulate organic matter flux and planktonic new production in the deep ocean, Nature, 282, 677680, 1979.

Evans, D. F. and Wennerström, H.: The Colloidal Domain: Where Physics, Chemistry, Biology, and Technology Meet, WileyVCH, 2. Edition, 1999.

Evans, G. T.: The role of local models and data sets in the Joint Global Ocean Flux Study, Deep-Sea Res. I, 46, 1369-1389, 1999.

Falkowski, P.: Rationalizing elemental ratios in unicellular algae, J. Phycology, 36, 3-6, 2000.

Fasham, M. J. R. and Evans, G. T.: The use of optimization techniques to model marine ecosystem dynamics at the JGOFS station at $47^{\circ} \mathrm{N} 20^{\circ} \mathrm{W}$, Philosophical Transactions of the Royal So- 
ciety of London, B348, 203-209, 1995.

Fasham, M. J. R., Sarmiento, J. L., Slater, R. D., Ducklow, H. W., and Williams, R.: Ecosystem behaviour at Bermuda Station"S" and Ocean Weather Station "INDIA": A general circulation model and observational analysis, Global Biogeochem. Cycles, 7(2), 379-415, 1993.

Geider, R. J. and LaRoche, J.: Redfield revisited: variability of $\mathrm{C}: \mathrm{N}: \mathrm{P}$ in marine microalgae and its biochemical basis, European J. Phycology, 37, 1-17, 2002.

Geider, R. J., MacIntyre, H. L., and Kana, T. M.: A dynamic regulatory model of phytoplankton acclimation to light, nutrients, and temperature, Limnol. Oceanogr., 43(4), 679-694, 1998.

Hood, R. R., Laws, E. A., Armstrong, R. A., Bates, N. R., Brown, C. W., Carlson, C. A., Chai, F., Doney, S., Falkowski, P. G., Feely, R. A., Friedrichs, A. M., Landry, M. R., Moore, J. K., Nelson, D. M., Richardson, T. L., Salihoglu, B., Schartau, M., Toole, D., and Wiggert, J. D.: Pelagic functional group modeling: Progress, challenges and prospects, Deep-Sea Res. II, 53(57), 459-512, 2006.

Jackson, G. A.: Aggregation in the marine environment, Environ. Sci. Technol., 32/19, 2805-2814, 1998.

Jackson, G. A.: Effect of coagulation on a model planktonic food web, Deep-Sea Res. I, 48, 95-123, 2001.

Kaehler, P. and Koeve, W.: Marine dissolved organic matter: can its C:N ratio explain carbon overconsumption?, Deep-Sea Res. I, 48, 49-62, 2001.

Körtzinger, A., Koeve, W., Kähler, P., and Mintrop, L.: C:N ratios in the mixed layer during the productive season in the northeast Atlantic Ocean, Deep Sea Res. I, 48, 661-688, 2001.

Kriest, I. and Evans, G. T.: Representing phytoplankton aggregates in biogeochemical models, Deep-Sea Res. I, 46, 1841-1859, 1999.

Krishnakumar, K.: Micro-genetic algorithms for stationary and non-stationary function optimization, Intellegent Control and Adaptive Systems, 1196, 289-296, 1989.

Lima, I. and Doney, S. C.: A three-dimensional, multinutrient, and size-structured ecosystem model for the North Atlantic, Global Biogeochem. Cycles, 18(3), GB3019, doi:10.1029/2003GB002146, 2004.

Logan, B., Passow, U., Alldredge, A., Grossart, H.-P., and Simon, M.: Rapid formation and sedimentation of large aggregates is predictable from coagulation rates (half-lives) of transparent exopolymer particles (TEP), Deep-Sea Res. II, 42, 203-214, 1995.

Mari, X. and Burd, A.: Seasonal size spectra of transparent exopolymeric particles (TEP) in a coastal sea and comparision with those predicted using coagulation theory, Mar. Ecol. Prog. Ser., 163, 63-76, 1998.

Mari, X., Beauvais, S., Lemée, R., and Pedrotti, M. L.: NonRedfield $\mathrm{C}: \mathrm{N}$ ratio of transparent exopolymeric particles in the northwestern Mediterranean Sea, Limnol. Oceanogr., 46(7), 1831-1836, 2001.

Marra, J.: ${ }^{14}$ C-uptake by phytoplankton, now and in the future., Limnol. Oceanogr. Bull., 12, 1-3, 2003.

Michaels, A., Bates, N., Buesseler, K., Carlson, C., and Knap, A.: Carbon-cycle imbalances in the Sargasso Sea., Nature, 372, 537540, 1994

Moore, K. J., Doney, S. C., Kleypas, J. A., David, M., and Fung, I. Y.: An intermediate Complexity Marine Ecosystem Model for the Global Domain, Deep-Sea Res. II, 49, 403-462, 2001.
Mopper, K., Zhou, J., Ramana, K. S., Passow, U., Dam, H. G., and Drapeau, D. T.: The role of surface-active carbohydrates in the flocculation of a diatom bloom in a mesocosm, Deep-Sea Res. II, 42, 47-73, 1995.

Orr, J.: Ocean Carbon-Cycle Model Intercomparison Project (OCMIP): Phase 1 (1995-1997), GAIM Report 7, IGBP/GAIM Office, EOS, Univ. New Hampshire, Durham, NH, 1999.

Pahlow, M.: Linking chlorophyll-nutrient dynamics to the Redfield $\mathrm{N}: \mathrm{C}$ ratio with a model of optimal phytoplankton growth, Mar. Ecol. Prog. Ser., 287, 33-43, 2005.

Passow, U.: Transparent exopolymer particles (TEP) in aquatic environments, Prog. Oceanogr., 55(3-4), 287-333, 2002.

Passow, U., Logan, B., and Alldredge, A.: The role of particulate carbohydrate exudates in the flocculation of diatom blooms, Deep-Sea Res. I, 41, 335-357, 1994.

Redfield, A. C., Ketchum, B. H., and Richards, F. A.: The influence of organisms on the composition of seawater, in: The Sea, vol. 2, edited by: Hill, M. N., Interscience, New York, 1-34, 1963.

Ruiz, J., Prieto, L., and Ortegón, F.: Diatom aggregate formation and fluxes: a modeling analysis under different size-resolution schemes and with empirically determined aggregation kernels., Deep-Sea Res. I, 49, 495-515, 2002.

Sambrotto, R. N., Savidge, G., Robinson, C., Boyd, P., Takahashi, T., Karl, D., Langdon, C., Chipman, D., Marra, J., and Codespoti, L.: Elevated consumption of carbon relative to nitrogen in the surface ocean, Nature, 363, 248-250, 1993.

Schartau, M.: Data-assimilation studies of marine, nitrogen based, ecosystem models in the North Atlantic Ocean, Ph.D. thesis (English version), Naturwissenschaftliche Fakultät der ChristianAlbrechts-Universität zu Kiel, 127 pp., 2001.

Schartau, M. and Oschlies, O.: Simultaneous data-based optimization of a 1D-ecosystem model at three locations in the North Atlantic Ocean: Part I - Method and parameter estimates, J. Mar. Res., 61/6, 765-793, 2003a.

Schartau, M. and Oschlies, O.: Simultaneous data-based optimization of a 1D-ecosystem model at three locations in the North Atlantic Ocean: Part II - Standing stocks and nitrogen fluxes, J. Mar. Res., 61/6, 795-821, 2003 b.

Schartau, M., Oschlies, O., and Willebrand, J.: Parameter estimates of a zero-dimensional ecosystem model applying the adjoint method, Deep-Sea Res. II, 48, 1769-1800, 2001.

Schneider, B., Engel, A., and Schlitzer, R.: Effects of depth- and $\mathrm{CO}_{2}$-dependent $\mathrm{C}: \mathrm{N}$ ratios of particulate organic matter (POM) on the marine carbon cycle, Global Biogeochem. Cycles, 18, GB2015, doi:10.1029/2003GB002184, 2004.

Smetacek, V. and Pollehne, F.: Nutrient cycling in pelagic systems: a reappraisal of the conceptual framework, Ophelia, 26, 401428, 1986.

Sorensen, J. and Siegel, D.: Variability of the Effective Quantum Yield for Carbon Assimilation in the Sargasso Sea, Deep-Sea Res. II, 48, 2005-2035, 2001.

Spitz, Y. H., Moisan, J. R., and Abbott, M. R.: Configuring an ecosystem model using data from the Bermuda Atlantic Time Series (BATS), Deep-Sea Res. II, 48, 1733-1768, 2001.

Takahashi, T., Broecker, W., and Langer, S.: Redfield Ratio Based on Chemical Data from Isopycnal Surfaces, J. Geophys. Res., 90, 6907-6924, 1985.

Toggweiler, J.: Carbon overconsumption, Nature, 363, 210-211, 1993. 
Toggweiler, J.: Vanishing in Bermuda, Nature, 372, 505-506, 1994. Vallino, J. J.: Improving marine ecosystem models: Use of data assimilation and mesocosm experiments, J. Mar. Res., 58, 117$164,2000$.

Van den Meersche, K., Middelburg, J. J., Soetaert, K., van Rijswijk, P., Heip, C. H. R. and Boschker, H. T. S.: Carbon-nitrogen coupling and algal-bacterial interactions during an experimental bloom: Modeling a ${ }^{13} \mathrm{C}$ tracer experiment, Limnol. Oceanogr., 49(3), 862-878, 2004.
Wanninkhof, R. and Knox, M.: Chemical enhancement of $\mathrm{CO}_{2}$ exchange in natural waters, Limnol. Oceanogr., 41/4, 689-697, 1996.

Wells, M.: A neglected dimension, Nature, 391, 530-531, 1998.

Zhou, J., Mopper, K., and Passow, U.: The role of surface-active carbohydrates in the formation of transparent exopolymer particles by bubble adsorption of sea water, Limnol. Oceanogr., 43(8), 1860-1871, 1998. 